\title{
Controlled Outgrowth of Dissociated Neurons on Patterned Substrates
}

\author{
D. Kleinfeld, K. H. Kahler, ${ }^{a}$ and P. E. Hockberger ${ }^{b}$ \\ Department of Molecular Biophysics, AT\&T Bell Laboratories, Murray Hill, New Jersey 07974
}

The cytoarchitecture of nervous tissue is lost during the dissociation procedures used to form primary cell cultures. As a first step toward reestablishing an ordered arrangement of these cells in vitro, we developed a set of procedures for patterning the outgrowth of cells cultured on 2-dimensional substrates. These procedures used a combination of surface chemistry and photolithographic techniques. The adhesive properties of either silicon or silicon dioxide (quartz) surfaces were controlled by covalently binding small organic molecules to the surface with silane coupling agents. The attachment and growth of either embryonic mouse spinal cells or perinatal rat cerebellar cells were found to be promoted by binding certain amine derivatives to the surface. In particular, cells grown on surfaces bound with diamines and triamines, but not with monoamines, formed cultures whose morphology was similar to that of cells cultured on conventional substrates, i.e., glass coated with poly(D-lysine). The attachment of cells to a substrate was inhibited by binding alkane chains (e.g., $n$-tetradecane) to the surface and plating the cells in media containing 5-10\% (vol/vol) serum.

Patterns of selected adhesivity were formed using photochemical resist materials and lithographic masking techniques compatible with the silane chemistry. Cultures of either spinal cord cells or cerebellar cells could be confined to square regions on the scale of $50 \mu \mathrm{m}$. Cerebellar cells could be confined to grow on lines with widths less than $10 \mu \mathrm{m}$. This width is comparable to the diameter of granule cell somata. The patterned growth of cerebellar cells was maintained up to $12 \mathrm{~d}$ in vitro. Over this time period the granule cells were observed to develop electrical excitability and immunoreactivity for neuron-specific enolase. Purkinje neurons also developed electrical excitability when grown on the chemically modified surfaces. Immunochemical reactivity of the patterned cultures for glial fibrillary acid protein

Received Sept. 15, 1987; revised Jan. 20, 1988; accepted Feb. 8, 1988.

Wc thank C. E. Chidscy, L. W. Jelinski, and G. N. Taylor for advice on silane chemistry, G. E. Blonder for advice on lithography, S. C. Fitzgerald for instruction on the spinal cord preparation, H.-Y. Tseng for advice on the cerebellar preparation, and $\mathrm{D}$. W. Tank for collaborating on preliminary aspects of this work. We thank B. Friedman for her comments on an early version of the manuscript. $\mathrm{K}$. H. K. was the recipient of an AT\&T Summer Research Project fellowship. P. E. H. was supported in part by Air Force Office of Scientific Research Grant F4962085-C-0009.

Correspondence should be addressed to David Kleinfeld, Room 6H-424, AT\&T Bell Laboratories, 600 Mountain Ave., Murray Hill, NJ 07974.

a Present address: School of Medicine, University of Michigan, Ann Arbor, MI 48109

${ }^{b}$ Present address: Department of Physiology, Northwestern University Medical School, Chicago, IL 60611 .

Copyright (c) 1988 Society for Neuroscience $0270-6474 / 88 / 114098-23 \$ 02.00 / 0$
(GFAP) showed that glia are patterned along with the associated granule cells. Interestingly, the GFAP-positive glia that proliferated on surfaces bound with amine derivatives attained primarily a tile-shaped, fibroblast-like morphology, while those proliferating on glass coated with poly(D-lysine) developed primarily a spindle-shaped, process-bearing morphology. Granule cells preferentially associated with the spindle-shaped glia.

Striking examples of highly stereotyped cytoarchitectures exist in the mammalian CNS. These include the cerebellar cortex, the hippocampus, the olfactory bulb, and the columnar organization of the cerebral cortex. The highly ordered arrangement of neurons in such regions has facilitated in vivo studies on cellular physiology (e.g., Eccles et al., 1977; Hubel and Wiesel, 1977), but it has proven difficult to probe collective properties of networks of neurons in vivo. One reason for this difficulty is that the 3-dimensional distribution of cells hinders the simultaneous recording of electrical activity at many sites in a region (e.g., Gerstein et al., 1983). Thus, it would be useful to construct 2-dimensional in vitro models that mimic the architecture observed in vivo. These models would aid in the study of developmental and computational properties of neural systems.

Culture systems formed from dissociated mammalian neurons provide a useful method for studying the physiology of neurons in a simplified, controlled environment (for review, see Fedoroff and Hertz, 1977; Fishbach and Nelson, 1977; Nelson and Lieberman, 1981). Unfortunately, the innate architecture of the neurons in the intact tissue is lost when these cultures are prepared. A number of investigators have attempted to restore order to the cultured cells by patterning their outgrowth (Carter, 1965; Ivanova and Margolis, 1973; Letourneau, 1975; Cooper et al., 1976; Furshpan et al., 1976; Albrecht-Buehler, 1979; Hammarback et al., 1985; Ireland et al., 1987). These studies addressed a number of critical issues in cellular development, such as the growth and guidance of cell appendages. However, the patterned outgrowth achieved by these investigators either had insufficient resolution or had insufficient viability to be useful in reestablishing neural architectures.

In this work a set of procedures was derived for patterning the attachment and outgrowth of dissociated neurons and their satellite cells on planar surfaces. We first identified a class of small silane derivatives that promoted cell adhesion and a class that prevented adhesion. These molecules, as opposed to polymers such as poly(D-lysine), could be covalently bound to the surface of silicon-based substrates (e.g., quartz). Long-lasting, high-resolution patterns of adhesion were formed by combining the silane chemistry with compatible photolithographic proce- 
dures. The minimum featurc of the final pattern was $5 \mu \mathrm{m}$. Neurons grown on these surfaces formed viable cultures that were faithful to the underlying pattern of adhesion for at least $12 \mathrm{~d}$ in vitro.

Studies were carried out using both dissociated spinal cord cells from embryonic mice (Ransom et al., 1977) and dissociated cerebellar cells from perinatal rats (Lasher and Zagon, 1972; Messer, 1977). We examined the gross morphology of cultures of both cell types on surfaces bound with various amine derivatives and, subsequently, on patterned surfaces. We then focused on forming high-resolution patterns using cerebellar cells. The architecture of the cerebellum has many simplifying features that suggest its use as a model system. Further, cultures could be selectively enriched for specific cerebellar neurons. The electrical activity and the immunochemical reactivity [neuron-specific enolase (NSE) and glial fibrillary acid protein (GFAP)] of cerebellar cells grown on the patterned substrates were studied. The development of neurons and glia on the patterned cultures were then compared with the results obtained for cells in vivo and for cells grown in explant cultures (Hockberger et al., 1987a).

Preliminary aspects of this work have been reported (Kleinfeld and Tank, 1986; Kleinfeld and Hockberger, 1987).

\section{Materials and Methods}

\section{Chemical and lithographic processing}

A sequence of processing steps was developed to define regions on a surface, either silicon or silicon dioxide (quartz), with the selected cell adhesion properties. In brief, the surface was coated with a photoresist, exposed through a lithographic mask containing the desired pattern and developed to etch the resist from the exposed areas. This formed an image of the desired pattern in the photoresist. Open areas in the resist pattern allowed alkane chains to be bound to the underlying surface. These areas formed regions of low cell adhesion. The resist pattern was subsequently removed and the previously protected areas were bound with amine derivatives. These areas formed regions that promoted cell adhesion.

Details of the processing steps, summarized in Figure 1, are given below. All silane chemicals were obtained from Petrarch Chemical (PA) and used without further purification. Crown glass coverslips $(18 \mathrm{~mm}$ diameter $\times 0.2 \mathrm{~mm}$ ) were obtained from Belco (NY), quartz discs ( 32 $\mathrm{mm}$ diameter $\times 1.3 \mathrm{~mm}$ ) from Esco $(\mathrm{NJ})$ and silicon wafers $(32 \mathrm{~mm}$ diameter $\times 0.5 \mathrm{~mm})$ and sodium-free borosilicate glass $(25 \mathrm{~mm} \times 25$ $\mathrm{mm} \times 0.5 \mathrm{~mm}$ ) from AT\&T Technologies (PA). All processing steps were performed in a laminar flow hood equipped with a HEPA air-filter (Envirco, NM).

Cleaning the surface. Substrates were cleaned to insure that the photoresist adhered to the surface and that the chemical processing steps occurred to completion. Greasy material was removed by rubbing the surface with filter paper saturated with Micro detergent (International Products, NJ), followed by a rinse in deionized water. Residual organic matter was removed by soaking the substrates, with mild agitation, for $10 \mathrm{~min}$ in a freshly prepared mixture of 9 parts concentrated $\mathrm{H}_{2} \mathrm{SO}_{4}$ and 1 part of $30 \% \mathrm{H}_{2} \mathrm{O}_{2}$. This acid-oxidizer wash was followed by a brief rinse with deionized water, a brief rinse in approximately $\mathbf{l} \mathbf{~}$ $\mathrm{NaOH}$ to neutralize any remaining acid, and then a rinse in approximately 20 changes of deionized water. Finally, the substrates were baked for approximately $60 \mathrm{~min}$ at $\geq 130^{\circ} \mathrm{C}$.

Lithographic definition of the surface. Conventional photolithographic techniques were employed (e.g., McGillis, 1983). However, the details of the processing steps were selected to be compatible with the subsequent chemical processing steps.

The surface was pretreated with hexamethyldisilazane (HMDS), a dehydration agent that increases the adhesion of the resist. The substrate was held in a vacuum chuck, a puddle of HMDS was applied to the surface, and the substrate was spun to dry in a wafer spinner (Headway Research, TX) operating at $2000 \mathrm{rpm}$ for approximately $20 \mathrm{sec}$ (step 1 in Fig. 1). Positive photoresist, Microposit 1450J (Shipley, PA), was immediately applied to the surface, and the wafer was spun at 4000 $\mathrm{rpm}$ for $30 \mathrm{sec}$. The resist coating was cured for $30 \mathrm{~min}$ at $90^{\circ} \mathrm{C}$. The

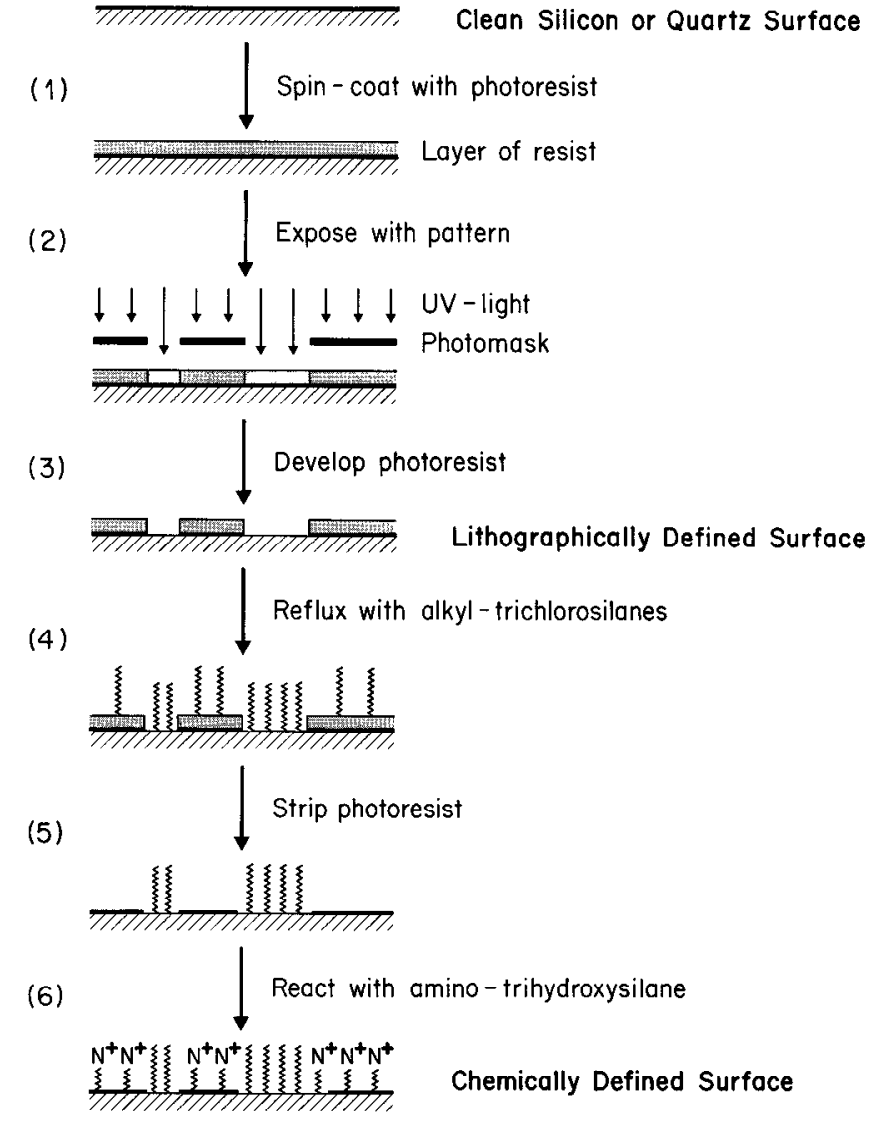

Figure 1. Schematic of the processing steps involved in chcmically patterning a silicon or silicon dioxide (quartz) substrate. Details are given in Materials and Methods. Note that the figure is not drawn to scale; the layer of photoresist is $\sim 1 \mu \mathrm{m}$ thick, while the alkanes and amines form layers of molecular thickness.

final thickness of the resist, measured with a depth gauge (Sloan Technology, CA), was $1.5 \mu \mathrm{m}$.

A high-resolution pattern was transferred to the resist by forming a contact print of the substrate with a mask containing the lithographic pattern (step 2 in Fig. 1). The substrate and mask were positioned in a contact printer (Karl Suss, VT), and the resist was exposed with collimated near-UV light, $16 \mathrm{~mW}$ of output power centered at $\lambda=320 \mathrm{~nm}$, for $14 \mathrm{sec}$. Following the exposure the photoresist was developed for $30 \mathrm{sec}$ in Microposit Developer (Shipley), diluted 1 part developer to 1 part deionized water, rinsed in deionized water, and blown dry with filtered $(<0.5 \mu \mathrm{m})$ air (step 3 in Fig. 1).

The coating of patterned resist was hardened by uniformly exposing the substrate to UV light, as above, followed by a bake at $100^{\circ} \mathrm{C}$ for 30 min. Photoresist that was initially exposed but not fully developed was removed by etching the substrates in an oxygen plasma (Technics West, CA) for $30 \mathrm{sec}$ at a pressure of $300 \mathrm{~m}$ Torr and a power of $300 \mathrm{~W}$.

Chemical definition of the surface. Alkane chains were covalently bound to the open areas on the surface by refluxing the substrates in a solution containing an alkyltrichlorosilane (step 4 in Fig. 1). This process involves direct nucleophilic substitution of a chlorine ion for a surface proton, forming a bond that binds the alkane to the surface (Pleuddemann, 1982; Leyden and Collins, 1980) (Fig. $2 A$ and item 5 in Fig. 3). Substrates were refluxed for $12-14 \mathrm{hr}$ in a $5 \%(\mathrm{vol} / \mathrm{vol})$ solution of the alkyltrichlorosilane dissolved in hexane. Hexane was chosen as the solvent because its boiling point $\left(90^{\circ} \mathrm{C}\right)$ was sufficiently high to drive the reaction to completion but low enough to avoid damage to the resist. The reaction step was followed by 2 reflux steps in pure hexane, lasting $1 \mathrm{hr}$ each, to remove polymers of the alkane that were noncovalently attached to the surface; substrates were not allowed to dry between these steps.

The pattern of photoresist remaining on the sample was removed (stripped) by sonicating the substrates in acetone (step 5 in Fig. 1). Two 
<smiles>C=CC(=C)C(O)(C=C)C(O)(O)C=C</smiles>

(B)Hydrolysis of Methoxysilanes Followed by Condensation of the Corresponding Silanol

$\mathrm{R}-\mathrm{Si}\left(\mathrm{OCH}_{3}\right)_{3}+3 \mathrm{H}_{2} \mathrm{O} \rightarrow \mathrm{R}-\mathrm{Si}(\mathrm{OH})_{3}+3 \mathrm{CH}_{3} \mathrm{OH}$ (fast)<smiles>[R][SiH2]O[Si](O)(O)O[Si](O)(O)O[Si](O)(O)[R]C(C)C</smiles>

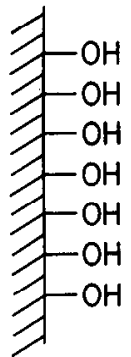<smiles></smiles>

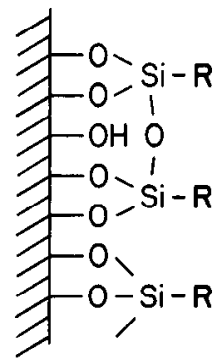

Figure 2. Schematic of the chemical reactions involved in binding functional groups to a surface. $A$, A functional group, designated $R$, forms the fourth ligand of a trichlorosilane. The chlorines undergo direct nucleophilic displacement by surface protons, covalently bonding the silane to the surface. This reaction is performed in an aprotic, organic solvent, such as hexane, under reflux conditions. $B$, A functional group forms the fourth ligand to a trimethoxysilane. The silane rapidly converts to the corresponding silanol in the presence of aqueous solvents, such as a mixture of water and alcohol. The hydroxy groups on the silanol condense with those on the surface, as well as with groups on other silanols. This condensation results in the covalent bonding of the silane, and short polymers of the silane, to the surface.

washes of $5 \mathrm{~min}$ each were used, followed by a brief rinse in propanol. Substrates were blown dry with filtered air. At this stage, the surface contained a pattern of alkylated regions and regions of bare silicon or quartz.

Amine derivatives were covalently bound to the unexposed regions of the surface, previously protected by the pattern of resist, by reacting the substrate with an aminotrihydroxysilane (step 6 in Fig. 1). An amine derivatized trimethoxysilane is hydrolyzed to the corresponding silanol, which then condenses with a surface proton and binds the amine to the surface (Pleuddemann, 1982; Leyden and Collins, 1980) (Fig. 2B and items $1-4$ in Fig. 3).

A $1.0 \%(\mathrm{vol} / \mathrm{vol})$ solution of the desired trimethoxysilane (Petrarch) was prepared in $95 \%$ ethanol and $5 \%$ deionized water, adjusted to $\mathrm{pH}$ 5.0 with acetic acid. The solution was prepared within $30 \mathrm{~min}$ of use to minimize crosslinking between the silanols. Substrates were placed in the solution for $30 \mathrm{sec}$ with constant agitation, briefly rinsed in 3 changes of ethanol, blown dry with filtered air, and baked in an air

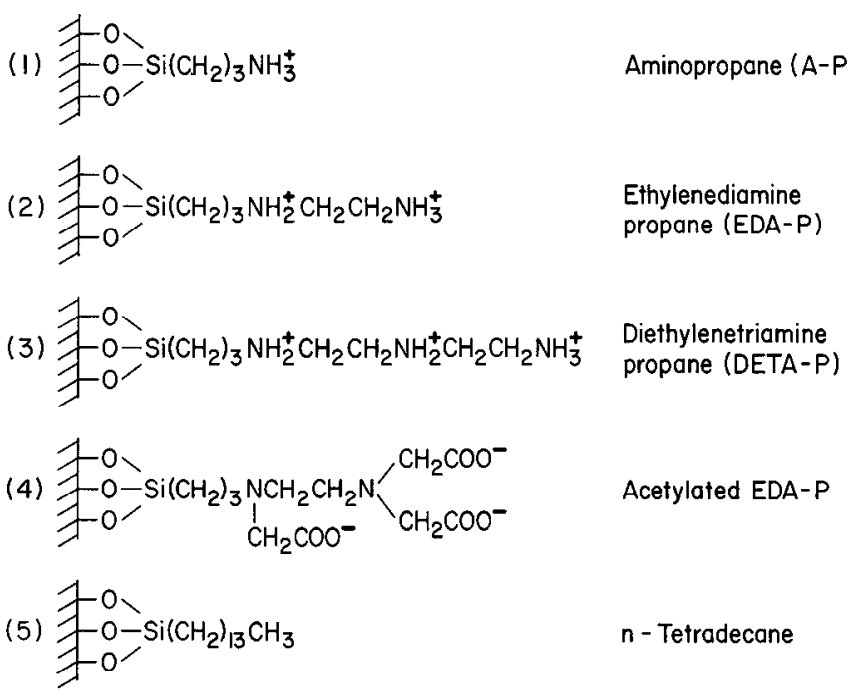

Figure 3. Structure of some of the functional groups that were bound to surfaces in these studies. The charge on the amine and acetyl groups refers to the ionization state of the group at $\mathrm{pH}$ 7.4.

atmosphere at $110-120^{\circ} \mathrm{C}$ for approximately $10 \mathrm{~min}$. The final baking completed the hydrolysis reaction. The surface now contained patterned alkylated regions and regions bound with amine derivatives.

It was possible to establish fiducials on silicon substrates so that the underlying chemical pattern could be discerned. A $0.2-\mu \mathrm{m}$-thick layer of $\mathrm{SiO}_{2}$ was thermally grown on the silicon prior to the lithographic processing steps (e.g., Vossen and Kern, 1978). After the lithographic pattern was transferred to the resist (step 3 in Fig. 1), the $\mathrm{SiO}_{2}$ was removed from the open regions by etching the substrate in buffered hydrofluoric acid (Transcene, MA) for $10 \mathrm{~min}$ at room temperature.

Sterilization. Silane-treated substrates were sterilized by heating them to $130^{\circ} \mathrm{C}$ for $30 \mathrm{~min}$ in a vacuum oven (NAPCo, NY). The oven was partially backfilled with nitrogen to limit oxidation. Alternately, samples were soaked in a mixture of $70 \%$ ethanol and $30 \%$ water for at least 30 $\min$.

\section{Coating surfaces with polyamino acids}

The long-chain polyamino acids poly(D-lysine) (Sigma, MO), poly(Darginine) (Sigma), poly(D-ornithine) (Sigma), and poly(D-glutamic acid) (Sigma), each with an average molecular weight between 70,000 and $150,000 \mathrm{Da}$, were prepared as $0.0025 \%$ (wt/vol) solutions in $100 \mathrm{~mm}$ boric acid, $\mathrm{pH}$ 8.4. Substrates were cleaned as described above and soaked in a solution of the desired polyamino acid for 20-40 hr. Coverslips were then rinsed in 3 changes of Dulbecco's phosphate-buffered salts (DPBS; Gibco, NY).

\section{Dissociation procedures}

Dissociated neurons were obtained from spinal cords of fetal mice and from cerebella of rat pups. The dissociation procedures were similar for both preparations. In brief, tissue was isolated, minced into small pieces, partially digested in trypsin, triturated in the presence of DNAse, and then filtered to remove debris. The dissociation procedures made use of a saline buffer (135 mM NaCl, $5.4 \mathrm{mM} \mathrm{KCl}, 180 \mu \mathrm{M} \mathrm{Na} \mathrm{HPO}_{4}, 220$ $\mu_{\mathrm{M}} \mathrm{KH}_{2} \mathrm{PO}_{4}, 10 \mathrm{~mm}$ HEPES, and $20 \mu \mathrm{M}$ Phenol red, $\mathrm{pH}$ 7.4) and a culture media [Minimal Essential Medium with Earle's salts but without glutamine (Gibco) supplemented with $35 \mathrm{~mm}$ glucose, $45 \mathrm{~mm} \mathrm{NaHCO}_{3}$ and $2 \mathrm{~mm}$ glutamine, $\mathrm{pH}$ 7.4].

Spinal cord cells. Dissociated cultures of spinal cord cells were obtained from embryos of C57 Black/6J mice (Jackson Laboratories, ME), aged E13-E14, using procedures modified from those of Ransom et al. (1977). Spinal cords were isolated from 2 separate liters of pups (approximately 20 animals) in saline buffer supplemented with $35 \mathrm{~mm}$ glucose and $45 \mathrm{~mm}$ sucrose. The cords were pooled, rinsed in 3 changes 
of buffer, and finely minced. The minced tissue was incubated at $37^{\circ} \mathrm{C}$ for $30 \mathrm{~min}$ in saline buffer that was further supplemented with $50 \mu \mathrm{M}$ trypsin. The digested tissue was then transferred to culture media supplemented with $5.0 \%(\mathrm{vol} / \mathrm{vol})$ heat-inactivated horse serum (HyClone, UT), $5.0 \%$ (vol/vol) fetal-calf serum (Gibco), and $1 \mu \mathrm{M}$ deoxyribonuclease; components in the sera inactivated the trypsin. Dissociated cells were harvested by triturating the tissue 10 times with a Pasteur pipet, waiting for intact pieces of tissue to settle (approximately $5 \mathrm{~min}$ ), and then collecting the supernatant; these steps were repeated approximately 3 times using pipets with tips of increasingly narrower bore. The supernatant from each of the trituration steps was pooled. The final yield was approximately $10^{6}$ cells/spinal cord.

Cerebellar cells. Dissociated cultures of cerebellar cells were obtained from Sprague-Dawley rats (CAMM Laboratories, NJ), aged P2-P5, following a procedure modified from that of Lasher and Zagon (1972) and Messer (1977). Cerebellar tissue was isolated from littermates (10-15 pups) in saline buffer supplemented with $5.5 \mathrm{~mm}$ glucose, $60 \mathrm{~mm}$ sucrose, $25 \mu \mathrm{M}$ amphotericin B, $10^{s}$ units/liter $(\sim 10 \mu \mathrm{M})$ penicillin, and $20 \mu \mathrm{M}$ streptomycin. The tissue was pooled, washed, and minced as described for the spinal cord cells. The minced tissue was enzymatically digested by further supplementing the saline buffer with $100 \mu \mathrm{M}$ trypsin. The tissue was incubated at $37^{\circ} \mathrm{C}$ for $5 \mathrm{~min}$ in a shaker bath $(100 \mathrm{rpm})$, after which the supernatant was collected and added to an equal volume of culture media that was supplemented with $5 \%(\mathrm{wt} / \mathrm{vol})$ trypsin inhibitor. The remaining tissue was resuspended in the trypsin-buffer solution, agitated for $2 \mathrm{~min}$, supplemented with $0.1 \mu \mathrm{M}$ deoxyribonuclease, and agitated for an additional $5 \mathrm{~min}$; the supernatant was collected as above. These steps were repeated 4 or 5 times. The supernatant from all dissociation steps, along with the remaining tissue, was pooled. The material was concentrated by centrifugation for $10 \mathrm{~min}$ at $100 \mathrm{~g}$, the supernatant was discarded, and the pellet was resuspended in culture media that was supplemented with $10 \%(\mathrm{vol} / \mathrm{rol})$ heat-inactivated horse serum. Cellular debris was removed by filtering the suspension through 10 layers of cheesecloth. The final yield was approximately $10^{7}$ cells/ cerebellum.

\section{Plating and maintenance}

The concentration of dissociated cells was estimated using a hemacytometer. Cells were plated into multiple-well culture dishes (Costar, MA): $22-\mathrm{mm}$-diameter wells for use with coverglass and $35-\mathrm{mm}$-diameter wells for other substrates. The typical plating density for either cell type was $5 \times 10^{5}$ cells $/ \mathrm{cm}^{2}$ on unpatterned surfaces and $8 \times 10^{5}$ cells $/ \mathrm{cm}^{2}$ on patterned surfaces (see Results). Approximately $90 \mathrm{~min}$ after plating, the medium was exchanged for culture medium supplemented with N3 nutrients (Romijn et al., 1982) and $10 \%$ (vol/vol) horse serum (see above). Cells and other material that remained unattached to the surface were removed by gently swirling the dish to suspend the unattached material prior to exchanging the media. Cultures were maintained in an incubator (NAPCo) at $37^{\circ} \mathrm{C}$ in an atmosphere containing $10 \%$ (vol/vol) $\mathrm{CO}_{2}$ and $100 \%$ humidity.

Some cerebellar cultures were maintained up to $30 \mathrm{~d}$ in vitro. The media in these cultures was exchanged every $3 \mathrm{~d}$ for culture media supplemented with $\mathrm{N} 3$ nutrients, $10 \%$ (vol/vol) horse serum, $20 \mathrm{~mm}$ $\mathrm{KCl}$ (Lasher and Zagon, 1972; Thangnipon et al., 1983), and $10 \mu \mathrm{M}$ cytosine arabinoside (Sigma) (Seil et al., 1980).

\section{Microscopy}

Cells cultured on transparent substrates were visualized in transmission using a Nikon (NY) Diaphot microscope equipped with phase-contrast optics. Those cultured on silicon substrates were visualized in reflection using a Zeiss (NY) UEM microscope equipped with differential-interference-contrast optics and UD series metallurgical objectives.

\section{Electrophysiology and immunocytochemistry}

Electrophysiological measurements of cerebellar neurons were performed using whole-cell patch-recording techniques as described by Hockberger et al. (1987a). Immunological staining for GFAP and NSE was performed as previously described (Hockberger et al., 1987a). Cultures used for immunohistochemistry were rinsed in DPBS, fixated in $4 \%$ (wt/vol) paraformaldehyde in $100 \mathrm{~mm}$ phosphate buffer, $\mathrm{pH} 7.4$, and stored, prior to staining, at $4^{\circ} \mathrm{C}$ in DPBS supplemented with $0.02 \%$ (wt/vol) $\mathrm{NaN}_{3}$.

\section{Results}

Our experimental strategy was to first identify a silyation process that promoted cell-surface adhesion and outgrowth. Toward this goal, we compared the gross morphology of cultures grown on the silyated surfaces with those grown on conventional substrates, i.e., coverglass coated with basic polyamino acids such as poly(D-lysine) ( $p-D-L)$. The use of $p-D-L$ as a surface coating is well established in neurobiology (Yavin and Yavin, 1974). This qualitative assay allowed a select number of suitable materials to be identified. We subsequently performed quantitative studies on the viability of cells grown on these surfaces, i.e., we characterized the optimal plating density for the cultures and studied the immunochemical reactivity and electrical properties of identified cell types. The silyation process judged optimal for promoting cell adhesion, along with a process that inhibited cell adhesion, was combined with lithographic procedures to form chemical patterns that modulated the spatial distribution of cell outgrowth.

All cultures assessed for viability and cell adhesion, using either p-D-L or silane-treated surfaces, were examined after 2 $\mathrm{d}$ in vitro unless otherwise indicated. Cultures used for immunocytochemical and electrical studies were examined at later times, as described.

\section{Cell adhesion on polyamino acid-coated surfaces}

A typical culture of spinal cord cells that were plated onto a pD-L-coated coverglass is shown in Figure $4 A$. The cells were uniformly dispersed across the surface. There was little evidence of clumping or aggregation of the cells, and there were many processes between neurons in the culture. Many of the neurons were phase bright (arrow, Fig. 4A), although this culture was too immature for the stereotypical round, phase-bright shape of the dorsal root ganglion (DRG) neurons to be distinguished from that of other spinal neurons. In general, the culture was similar in gross morphology to those described by Ransom et al. (1977).

A typical culture of cerebellar cells plated and maintained on a p-D-L-coated surface is shown in Figure $5 A$. Cells with 8- to $10-\mu \mathrm{m}$-diameter somata that appeared phase-bright, indicative of immature granule neurons, were uniformly dispersed throughout the culture (arrow, Fig. 5A). Larger, flat cells, indicative of glia and fibroblasts, were also apparent. No incidents of cell clumping or excessive aggregation were observed in these cultures. As with the spinal cord cells, the general morphology of this culture compared favorably with previous descriptions (Lasher and Zagon, 1972; Messer, 1977).

We checked if dissociated cells would adhere to polymers other than p-D-L. Cells were plated onto glass surfaces coated with either poly(D-arginine) or poly(D-ornithine). Cultures of spinal cord cells and of cerebellar cells appeared indistinguishable from similar cultures plated onto p-D-L (Figs. $4 A$ and $5 A$ ). In contrast, cultures of either cell type adhered poorly when plated onto surfaces coated with the negatively charged polymer poly(D-glutamic acid). The cells formed sparse, large clumps on the surface.

These experiments suggest that the presence of an amine group is a common factor in promoting cell adhesion. This observation is in agreement with results for cultures of other cell types (Harris, 1973; McKeehan and Ham, 1976; Ruegg and Hefti, 1984). We consequently limited our search for silanes that would promote cell adhesion to aminosilanes. 

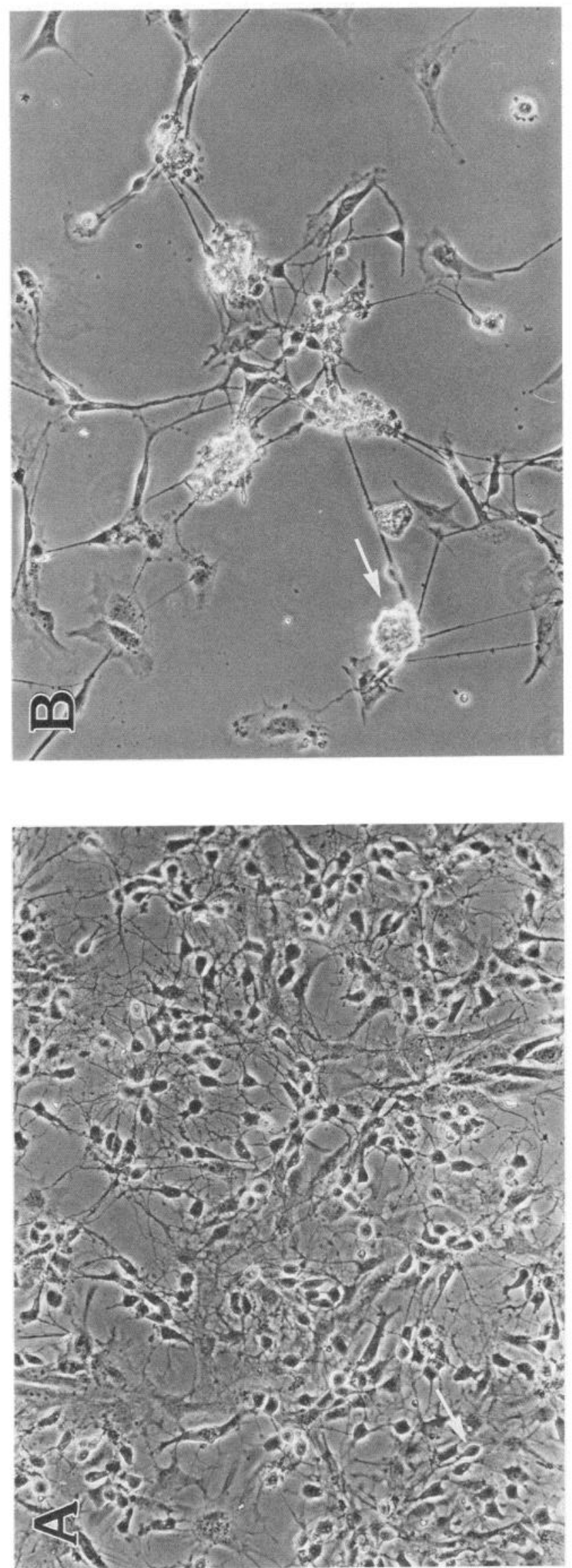
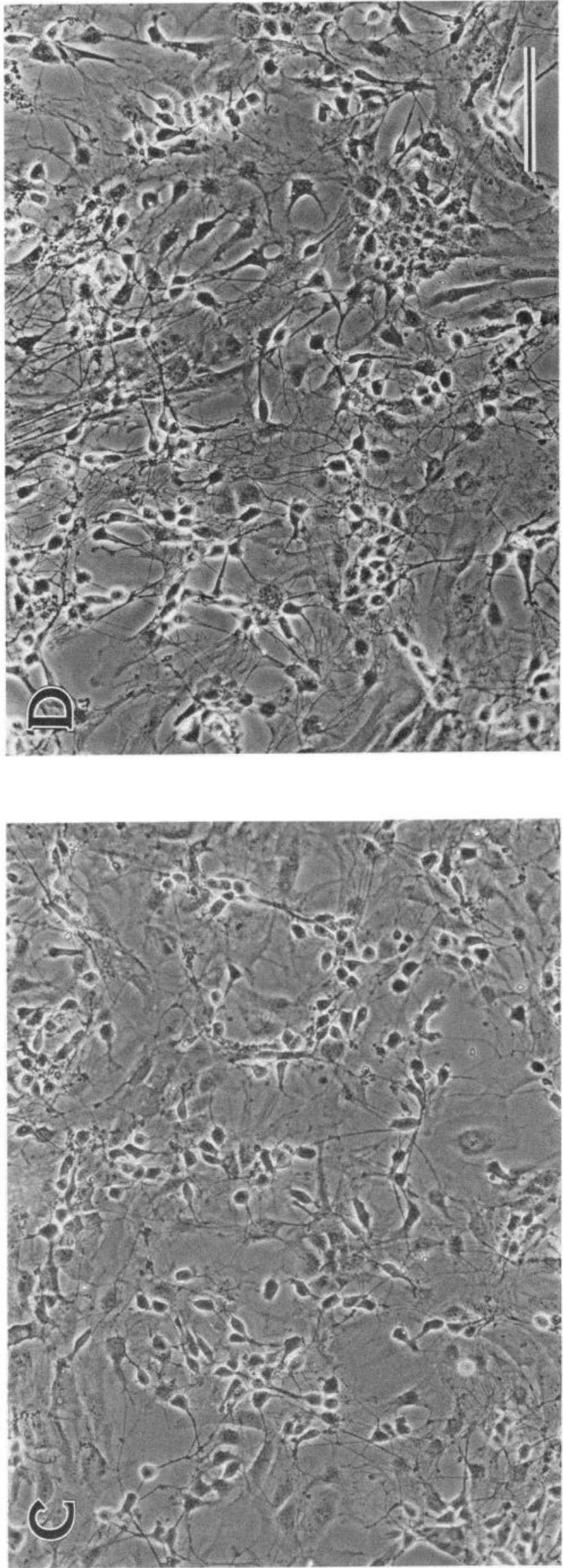


\section{Aminosilanes that promote cell adhesion}

The physical properties of long amine polymers, as opposed to small amine derivatives, make them unsuitable for use in forming patterned surfaces. The polymers form highly crosslinked structures that adhere to surfaces, and each other, via weak electrostatic forces (Nevo et al., 1955). Crosslinking between different polymers can distort the boundaries between regions selected to promote cell adhesion and those selected to inhibit adhesion. Further, the inability of these materials to form covalent bonds with the surface makes their use with lithographic techniques problematic.

Monoamines versus diamines and triamines. We examined the adhesion characteristics of cells plated onto surfaces bound with a series of progressively more complicated amine derivatives, all spaced from the surface by a propyl group. This series was comprised of the monoamine amino-propyl silane (A-P; Fig. $3 A$ ), the diamine ethylenediamine-propyl silane (EDA-P; Fig. $3 B$ ), and the triamine diethylenetriamine-propyl silane (DETA-P; Fig. 3C). In each experiment, neurons were concurrently plated onto coverglass coated with p-D-L, as a control.

A culture of spinal cord cells that were plated onto coverglass derivatized with the monoamine A-P (Fig. 3) is shown in Figure $4 B$. In contrast to the adhesion of cells on $\mathrm{p}$-D-L-coated surfaces, cells cultured on A-P-derivatized glass formed large clumps (arrow, Fig. $4 B$ ). Cerebellar cells plated onto glass substrates derivatized with A-P behaved similarly to spinal cord cells (cf. Figs. $4 B$ and $5 B$ ). The clumps observed with either cell type consisted of a large flat cell, directly attached to the surface, and a cluster of relatively small cells (arrow, Figs. $4 B$ and $5 B$ ). These results indicate that surfaces bound with A-P provide a poor substrate for cell adhesion.

Wc next cxamined cell adhesion on surfaces bound with the longer, multiply charged aminosilanes EDA-P and DETA-P. Cultures of spinal cord cells plated onto coverglass derivatized with EDA-P and with DETA-P are shown in Figures $4, C$ and $D$, respectively. Cells maintained on EDA-P surfaces were uniformly dispersed across the substrate and did not form clumps. These cultures were morphologically indistinguishable from those plated on p-D-L surfaces (cf. Figs. 4, $A$ and $C$ ). Cultures of spinal cells plated on DETA-P exhibited some clumping, but otherwise appeared similar to cultures on p-D-L surfaces (cf. Figs. 4, $A$ and $D$ ).

Cultures of cerebellar cells plated onto surfaces derivatized with EDA-P and with DETA-P are shown in Figures 5, $C$ and $D$, respectively. The gross morphology of these cultures were similar to cultures plated onto p-D-L-coated glass (cf. Figs. 5, $A, C$, and $D$ ). However, the long-term survival of cerebellar neurons on DETA-P surfaces was poor; most neurons detached after 3-5 din vitro.

Surfaces bound with EDA-P appeared to be the best substrate for the growth of spinal cord cells and cerebellar cells. Cultures of either cell type remained viable on these surfaces for up to $30 \mathrm{~d}$ in vitro.
Effects of structural variations in the amines. Monoamines that are bound to a surface via a propyl spacer, i.e., A-P, are reported to form an open ring structure (Leyden and Collins, 1980); the propyl chain bends as the positive amine opposes an hydroxy group on the surface. The possibility that cells adhered poorly to A-P bound surfaces because of this special structure, and not because of the unitary charged group, was examined by 2 methods.

In one experiment, spinal cord cells were cultured on glass substrates bound with a monoamine using either ethyl or butyl spacer groups, as well as the propyl spacer. The surface structure formed with the ethyl or butyl spacers differs from that of an open ring (Leyden and Collins, 1980). The gross morphology of cultures grown on surfaces derivatized with any one of these molecules was essentially identical. In a second experiment, spinal cells were cultured on glass substrates bound with A-P analogs in which a methyl group was substituted for either 1 , 2 , or all 3 of the protons on the amine. Essentially no change in cell adhesion was found with any of these derivatives relative to cultures maintained on surfaces bound with A-P.

We examined whether cell adhesion promoted by ethylenediamine (EDA) was dependent on the length of the spacer group between the EDA and the surface. Cells were cultured on surfaces bound with EDA via the relatively long spacer group, methyl-o-phenyl-propyl, in addition to surfaces bound with EDA-P. The gross morphology of either cultures of spinal cord cells or cerebellar cells maintained on surfaces using the longer spacer group were essentially identical to those using EDA-P.

The role of the positive charges on EDA in promoting cell adhesion, as opposed to structural or unknown systematic effects, was also tested. Spinal cells were cultured on surfaces bound with acetylated EDA-P, a negatively charged derivative of EDA-P (item 4 in Fig. 3). Cells generally failed to adhere to this surface. Those that did adhere formed small isolated clumps. The morphology of these cultures was similar to that observed using glass coated with poly(D-glutamic acid) (see above).

Effects of plating conditions. The above studies indicate that both spinal cord cell cultures and cerebellar cultures exhibit essentially the same gross morphology on EDA-P-derivatized glass as they attain on conventional, p-D-L-coated surfaces. To determine if unknown impurities in the coverglass affected the adhesion properties of the surface, we cultured cells on (relatively pure) silicon and quartz substrates derivatized with EDA$P$. The gross morphology of either spinal cord cell cultures or cerebellar cultures was observed to be unaffected by the choice of substrate.

We checked if the adhesive properties of the derivatized surfaces depended on the presence of serum in our plating media. Dissociated cerebellar cells were plated on A-P-, EDA-P-, and DETA-P-derivatized coverglass and derivatized quartz substrates, as well as on p-D-L-coated glass, with serum omitted from the plating media. No effect was observed on the distribution of cells in these cultures relative to those plated in the presence of serum.

Figure 4. Cultures of dissociated spinal cord cells after $2 \mathrm{~d}$ in vitro. The cells were plated and maintained in media containing $5 \%$ (vol/vol) fetal calf scrum and 5\% (vol/vol) horse serum. $A$, Cells plated onto covcrglass coatcd with poly(D-lysinc) (p-D-L); this culture serves as a control. The arrow points to a phase-bright cell, putatively a DRG neuron. $B$, Cells plated onto glass bound with aminopropylsilane (A-P). The arrow points to a clump of cells. $C$, Cells plated onto glass bound with ethylenediaminepropylsilane(EDA-P). $D$, Cells plated onto glass bound with diethylenetriamine (DETA-P). Note that the gross morphology of the cultures maintained on EDA-P and DETA-P bound glass resembles that of cells cultured on p-D-L-coated substrates, while those cultured on A-P are highly clumped. Scale bar, $100 \mu \mathrm{m}(A-D)$. 

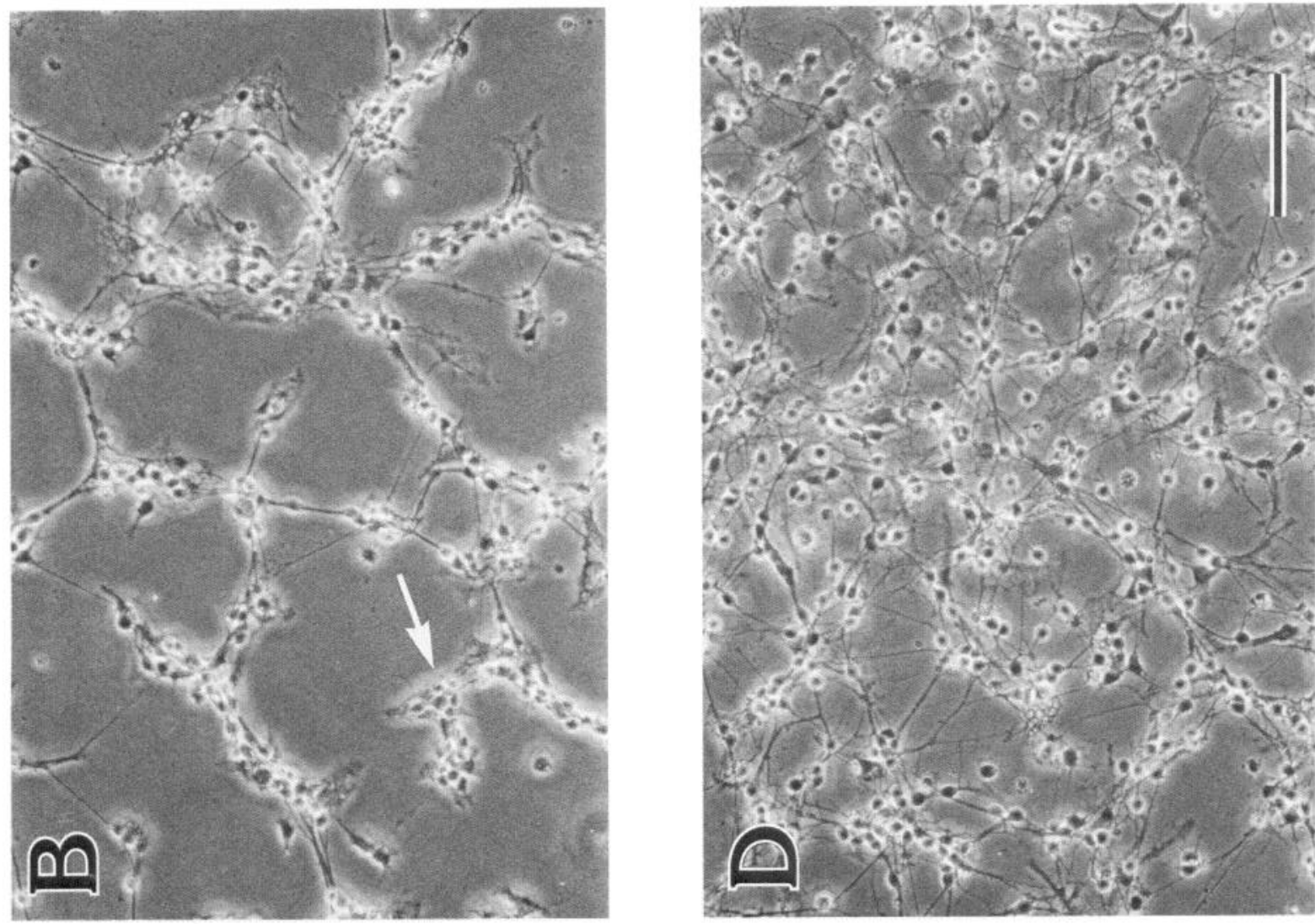

总용

要题品

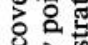

옹

造莺

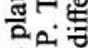

这安

$\rightarrow$.

룰.

总实

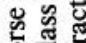

요의

ㅎํㄷㄷㅏ.

월

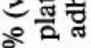

을을

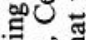

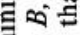

픙 ํํํ

물

远安

.

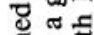

둘

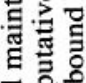

要
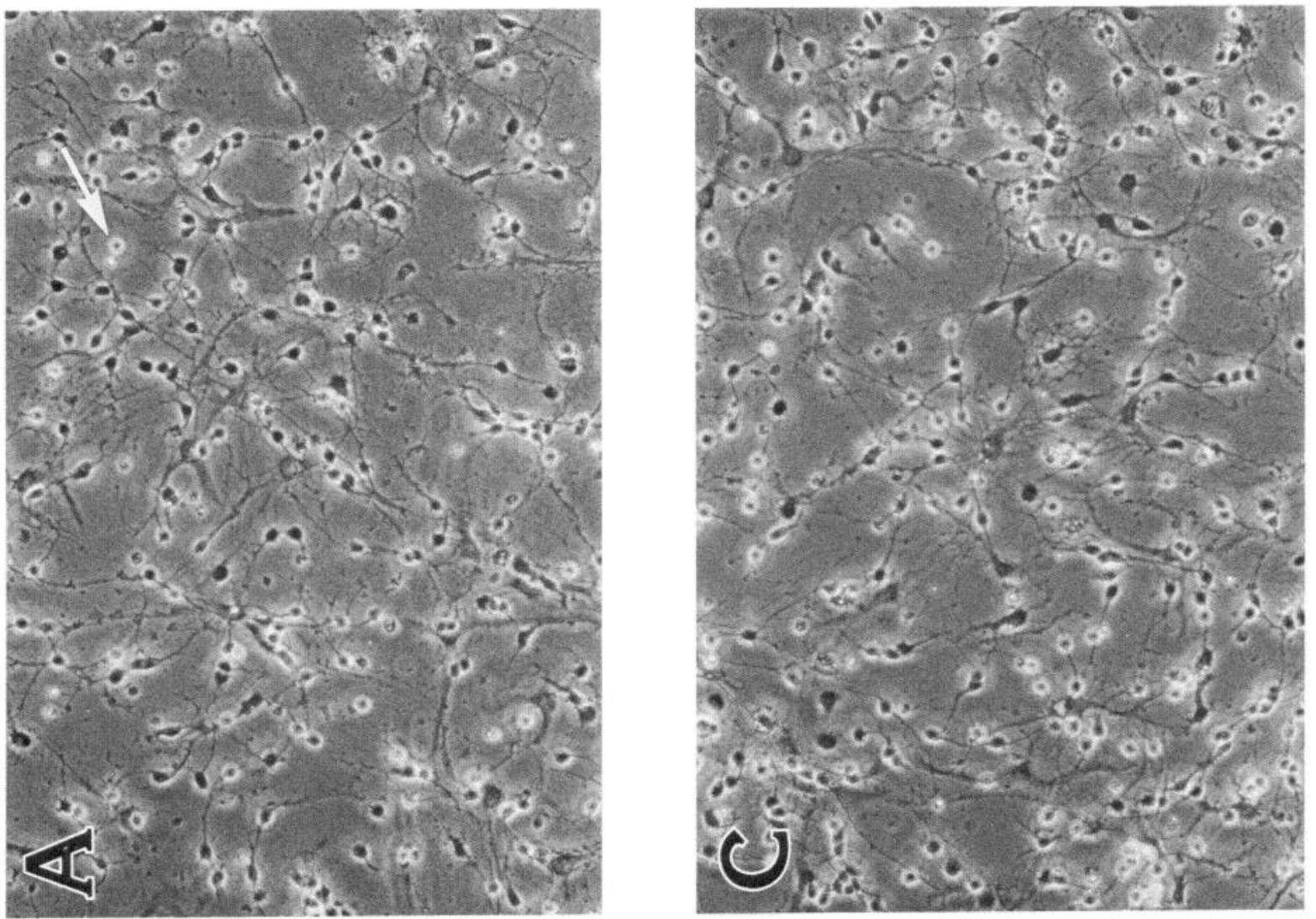

प्र 8

혐. 응

ㄴㅇㅇㄹㅣ

3 응

듬음용

을

U.

. $0 \%$

soi

छे

옹뵤

䟱

त्ल

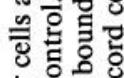

牙 80

हैं

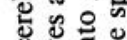

ठํㅝ

过

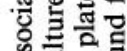

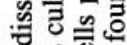

解记

证

包舟

当咜带

후을

的定

홍혀을 


\section{Surfaces that inhibit cell adhesion}

Certain hydrophobic surfaces are reported to inhibit cell adhesion (Carter 1968; Ivanova and Margolis, 1973; Bray, 1984). We thus investigated the adhesive properties of cells plated on surfaces bound with alkane chains as a means of producing silyated surfaces that inhibited cell attachment. Alkyltrichlorosilanes with 1 of 4 functional groups were considered: ethane, $n$-butane, $n$-octane, and $n$-tetradecane. Note that $n$-tetradecyltrichlorosilane (item 5 in Fig. 3) was the highest molecular weight alkyltrichlorosilane that was sufficiently soluble in hexane for use in our processing steps.

The presence of serum in the media was found to play a crucial role in preventing the attachment of cells onto our alkylated surfaces. Cerebellar cells plated onto either silicon or auartz surfaces derivatized with any of the alkanes tested were obs $r$ rved to attach to the surface, albeit in clumps, if the plating tedia did not contain serum. In contrast, both cerebellar cells and spinal cord cells failed to adhere to the alkylated surfaces if the media contained serum. The generally poor adhesion of cells on alkylated surfaces prevented us from quantitatively determining the minimum concentration of serum required to inhibit adhesion. However, cells plated in either 5 or $10 \%(\mathrm{vol} / \mathrm{vol})$ serum consistently did not adhere to $n$-tetradecane-bound surfaces; we return to this issue in the next section.

The choice of material used as a substrate was found to be an additional factor in preventing the attachment of cells to a surface. Dissociated spinal cord cells and cerebellar cells adhered in clumps to coverglass derivatized with any of the alkanes tested. Similar results were found using sodium-free borosilicate glass as the substratc. Thesc results imply that silicon or quartz substrates, with their pure composition, must be used for forming patterns.

\section{Cell adhesion on chemically patterned surfaces}

Chemically patterned surfaces were prepared as described in Materials and Methods (Fig. 1). The compound EDA-P was used to form regions that promoted cell adhesion and $n$-tetradecane was chosen to form regions that inhibited adhesion. Either silicon substrates, which allow the use of fiducials, or quartz substrates were employed. The patterns used for the studies in this section were selected for purposes of demonstrating the technique and not to suggest a specific architecture. In a later section we describe patterns that may be appropriate for cerebellar cells.

Cell segregation during plating. How do the cells segregate on the surface immediately after plating? Dissociated cerebellar cells were plated onto a silicon surface patterned with a grid-like feature. The grid was constructed from $15-\mu \mathrm{m}$-wide lines that were highlighted by $\mathrm{SiO}_{2}$ fiducials. The distribution of cells on the surface was recorded at $2-5$ min intervals after plating. The experiment was performed on a vibration-free table (Newport, CA) to prevent agitation of the culture.

Within 10 min after plating the cells formed a uniform distribution across the surface (Fig. $6 A$ ). No migration of the cells from alkylated regions of the surface to regions bound with EDA-P was observed during the first hour after plating. After this time the culture was gently swirled, and the plating media, along with the loose cells, was exchanged for fresh culture media (see Materials and Methods). Cells were observed to adhere primarily to the underlying adhesive pattern (Fig. 6B).
Slight agitation of a newly plated culture caused cells that rested on alkylated regions to move along the surface. Many of these cells subsequently stuck to the adhesive regions on the surface. Thus, agitation could be used to segregate the cells on the patterned surfaces.

Necessity of serum for patterned growth. Alkylated surfaces completely inhibited cell adhesion only if serum was present in the plating media (see previous section). To further examine the necessity of serum for patterning cell adhesion, we prepared two cultures, one plated without serum in the final media and the other plated with $10 \%(\mathrm{vol} / \mathrm{vol})$ horse serum present. The concentration of serum was adjusted by diluting fractions of the dissociated cells into media either with or without serum (see Materials and Methods).

Figure 7 shows cerebellar cultures, after $1 \mathrm{~d}$ in vitro, grown on surfaces patterned with grid-like design. Cells plated without serum in the final media adhered to many regions on the surface that were bound with $n$-tetradecane (Fig. $7 A$ ). Little evidence of the underlying chemical pattern is discernible in the pattern of cellular adhesion. Cells derived from the same preparation and plated in culture media containing $10 \%(\mathrm{vol} / \mathrm{vol})$ horse serum adhered in a manner that was faithful to the underlying chemical pattern (Fig. 7B).

Effects of intermediate processing steps. The processing steps used to chemically pattern the surfaces entail a number of intermediate procedures, such as the deposition and removal of a photoresist mask. These steps may, in principle, affect the adhesive properties of the surface. Thus, control experiments were performed to establish that the patterning of cells resulted from the binding of silane molecules and not from an artifact of the processing.

Two sets of silicon substrates were prepared: one following our standard procedures and one in which the solutions used in the deposition steps were devoid of the silane coupling agents. Dissociated spinal cord cells plated onto these substrates and maintained for $1 \mathrm{~d}$ in vitro are shown in Figure 8. Cells that were plated on lithographically processed substrates that were not silyated did not pattern. The cells formed large clusters on the surface (upper arrow, Fig. $8 \mathrm{~A}$ ) and tended to avoid regions that were marked by $\mathrm{SiO}_{2}$ fiducials (lower arrow, Fig. 8A). Cells plated onto substrates whose processing included the silyation steps adhered in a pattern that reflected the underlying chemical pattern. Uniform cell growth was observed in areas bound with EDA-P (arrow, Fig. 8B), while the alkylated regions contained relatively few cells. These results show that our chemical processing steps are required for the formation of high-resolution patterns of cell outgrowth.

Additional examples of spinal cord cells plated and maintained on patterned surfaces are shown in Figure 9. Cells growing in relatively large regions formed uniformly dispersed cultures (Fig. 9A). The growth in these regions typically stopped in an abrupt manner at the border of the adhesive region (upper arrow, Fig. 9A). There were incidents, however, in which cell processes migrated from the EDA-P bound regions onto the $n$-letradecane bound background (lower arrow, Fig. 9A). This implies that cells occasionally explored the background region. The spinal cells were observed to adhere reliably, without clumping, to square regions $70 \mu \mathrm{m}$ or more on edge (Fig. 9C).

A similar set of experiments was performed with cerebellar cells (data not shown). These cells adhered poorly to all regions of substrates that were not silyated; only a relatively small number of clumps of cells were observed. As illustrated in the next 


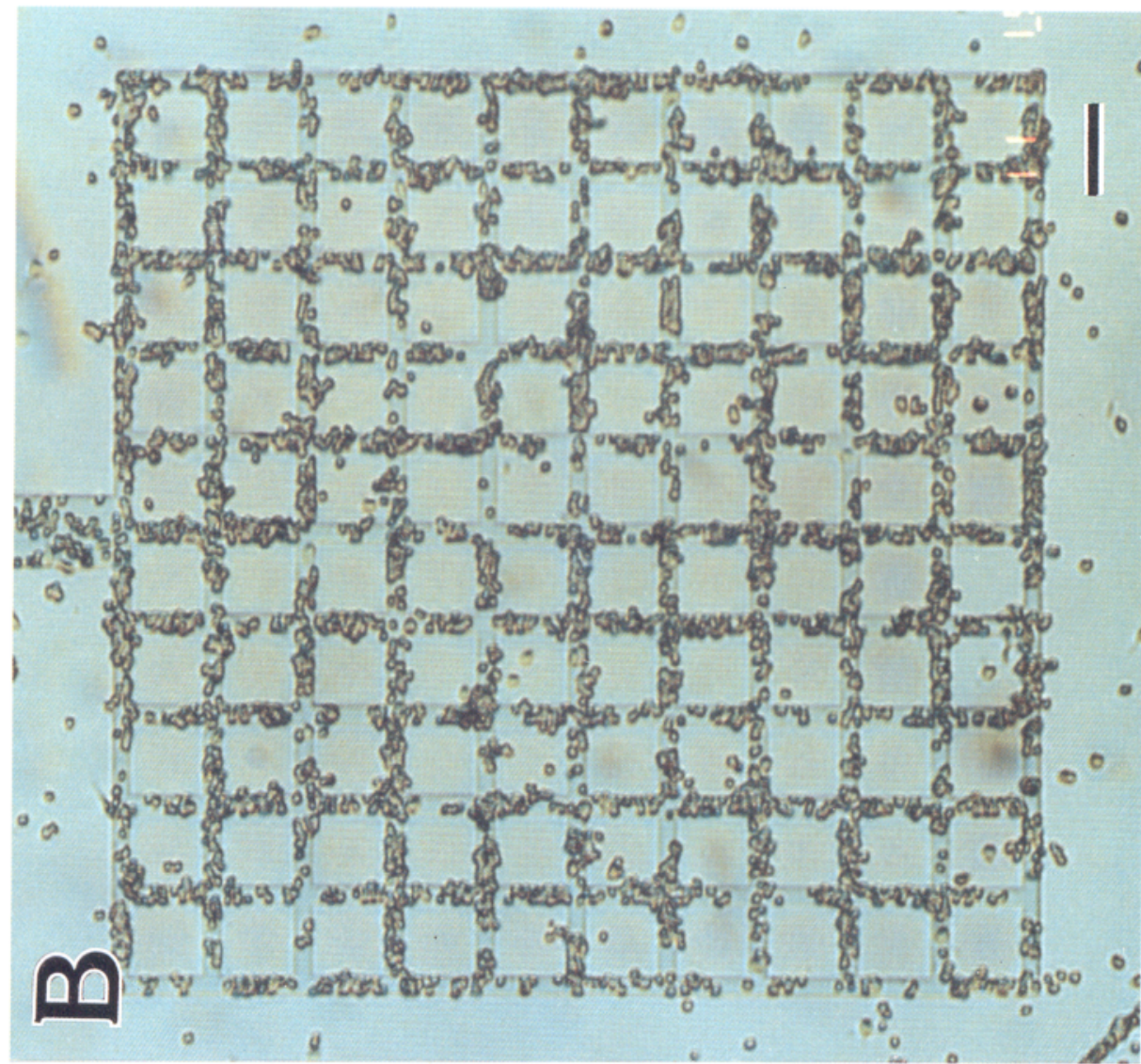

高. जू

要

要焉

实它寻实

政 总

论造

을 토

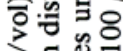

के हैं

吕

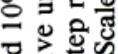

उ.

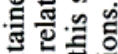

ठำ

जै

z

楁

둥

立起

का

․․․․

촌으융

灵实学

을 छ

जे

के

啳哭

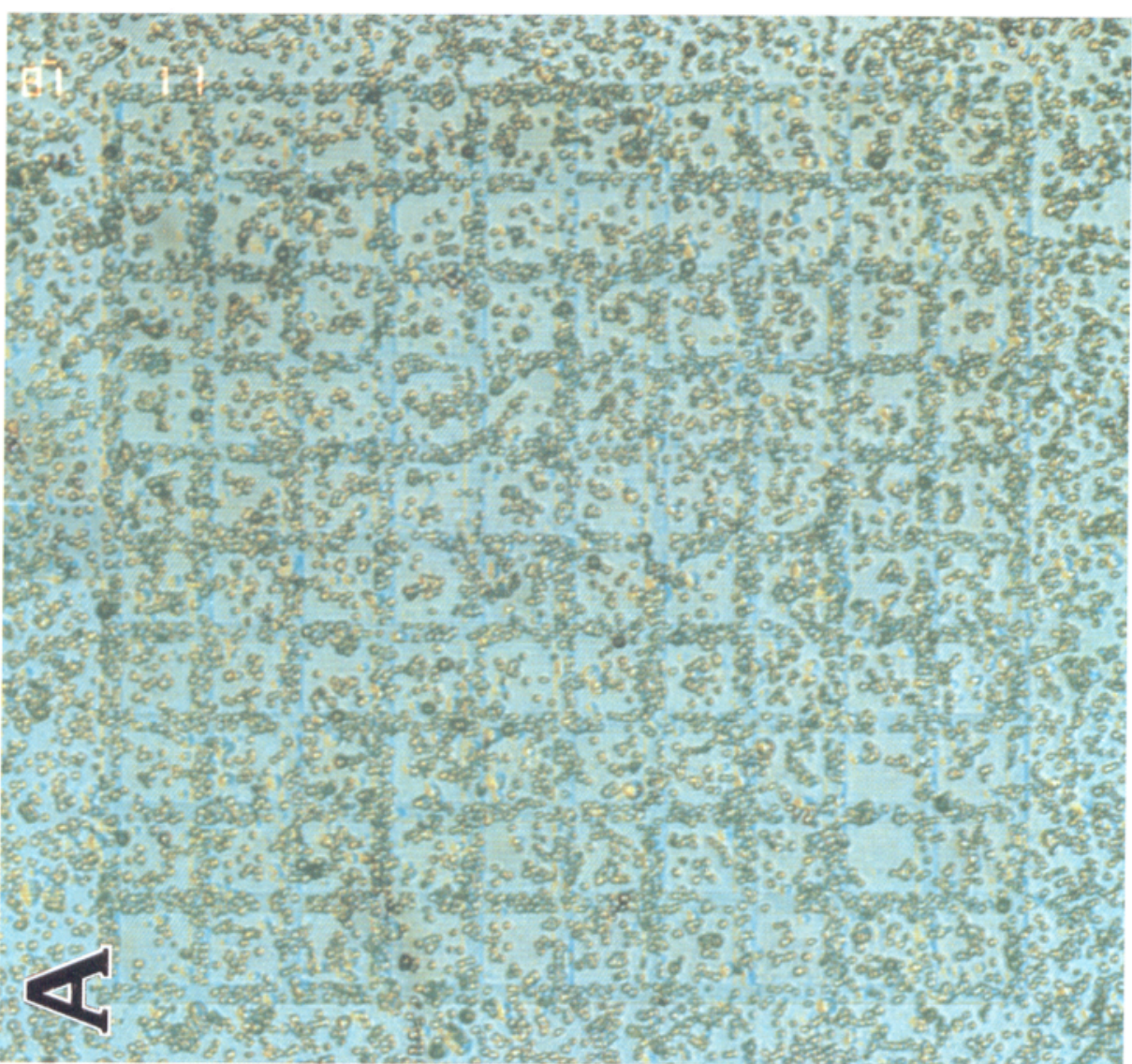




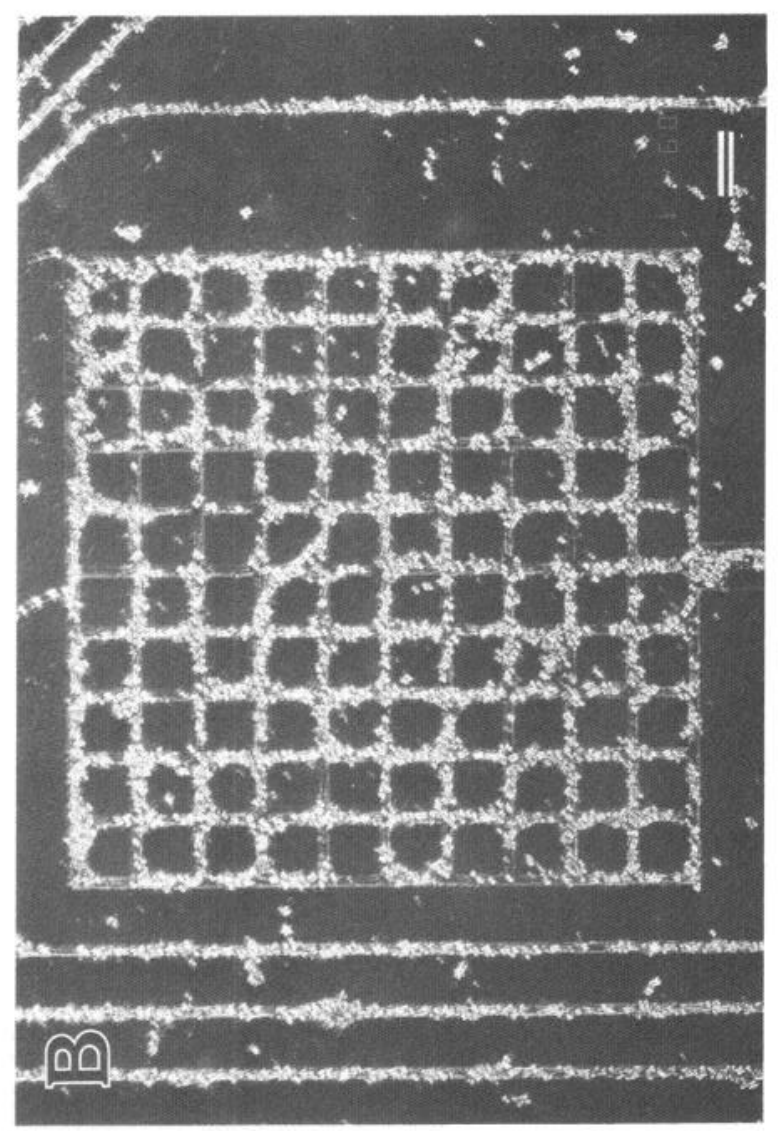

몰.

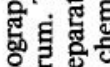

옹. 이

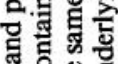

๑ :

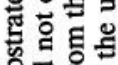

क궘넝

드ㅇㅝㅗㄹ

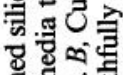

E

记

츨 글

일롤

엉

조욜

ธิ ๖्ड̃

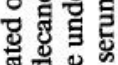

몀 正

过导。

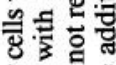

혁웡

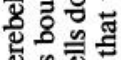

造造

땡월

总数

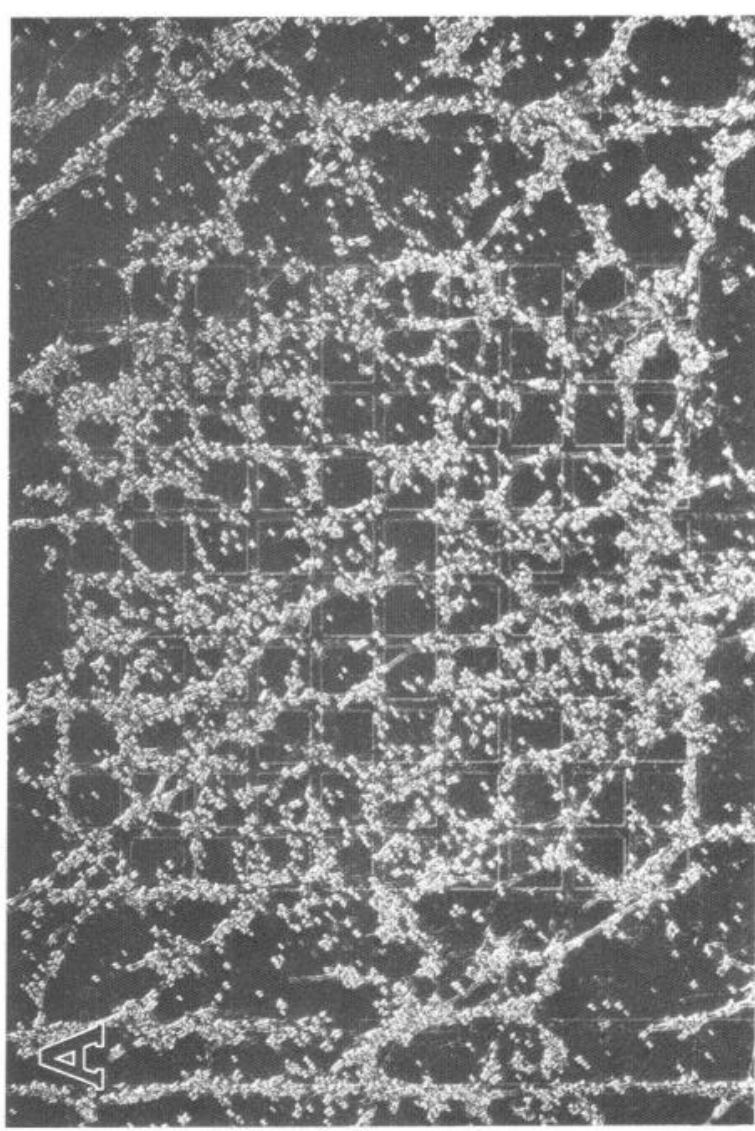

용을

홀

牙苍

턴됭ํㅇ

品

옹

园证

总。ㅇㅇㅇ

息

罗疮

8ี융.

눙

可 동

号氖爱

융 E

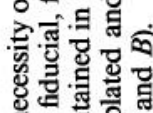

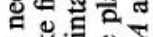

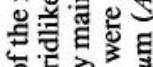

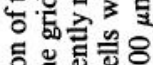

흘 힐응

대ㅇㅛㅛ

春孚㝴

政数

드잉

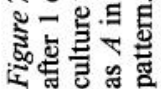




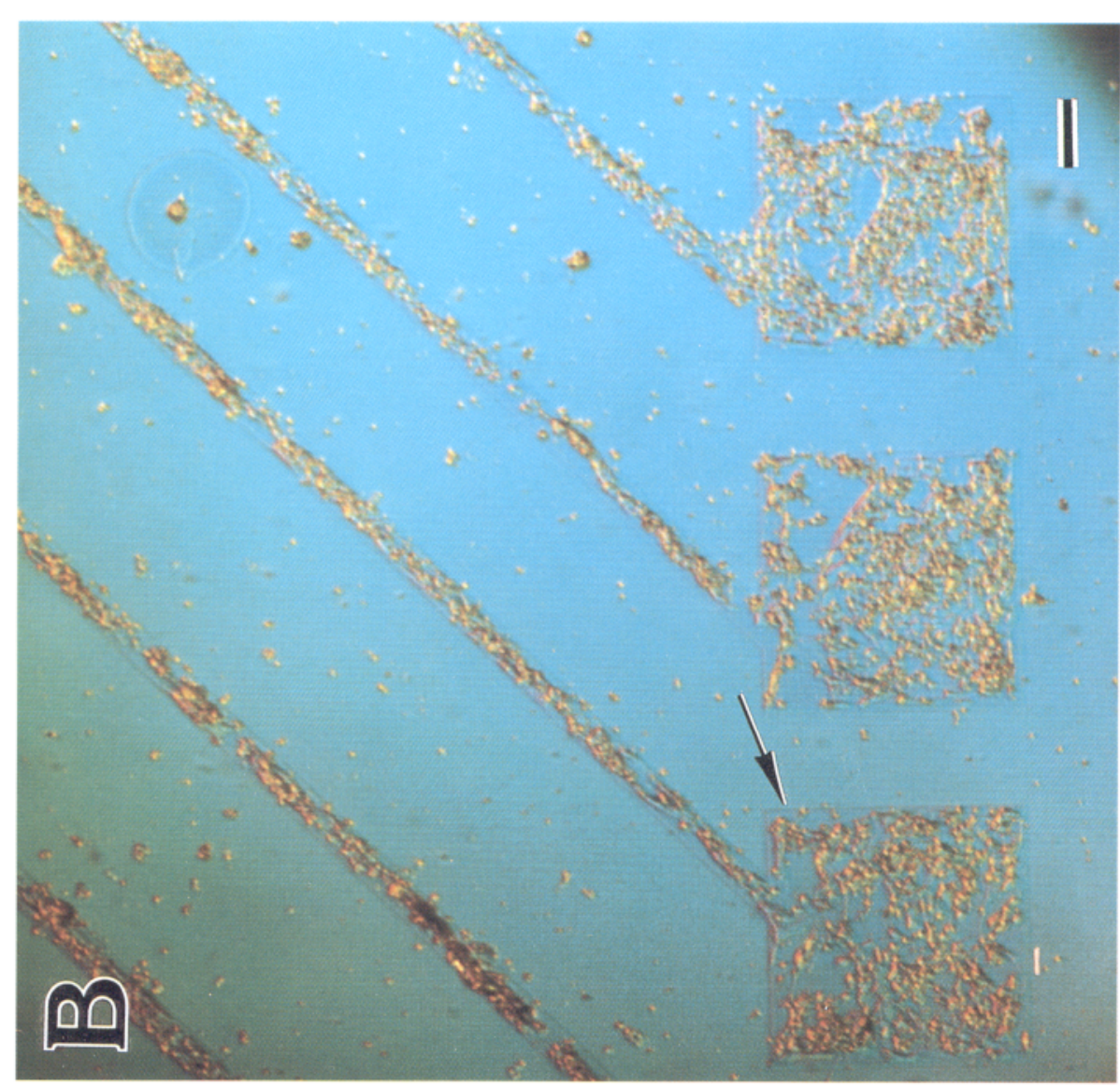

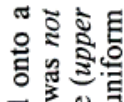

尊兽

흠

边兽

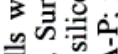

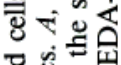

강.

흥 흘

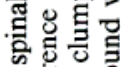

它釆。

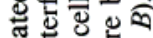

.

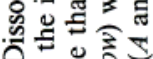

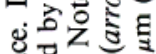

峞

들

क

to

\%

w응 娄

氙产灾

政

을. 政打 호.

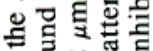
ठำ 品

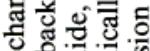

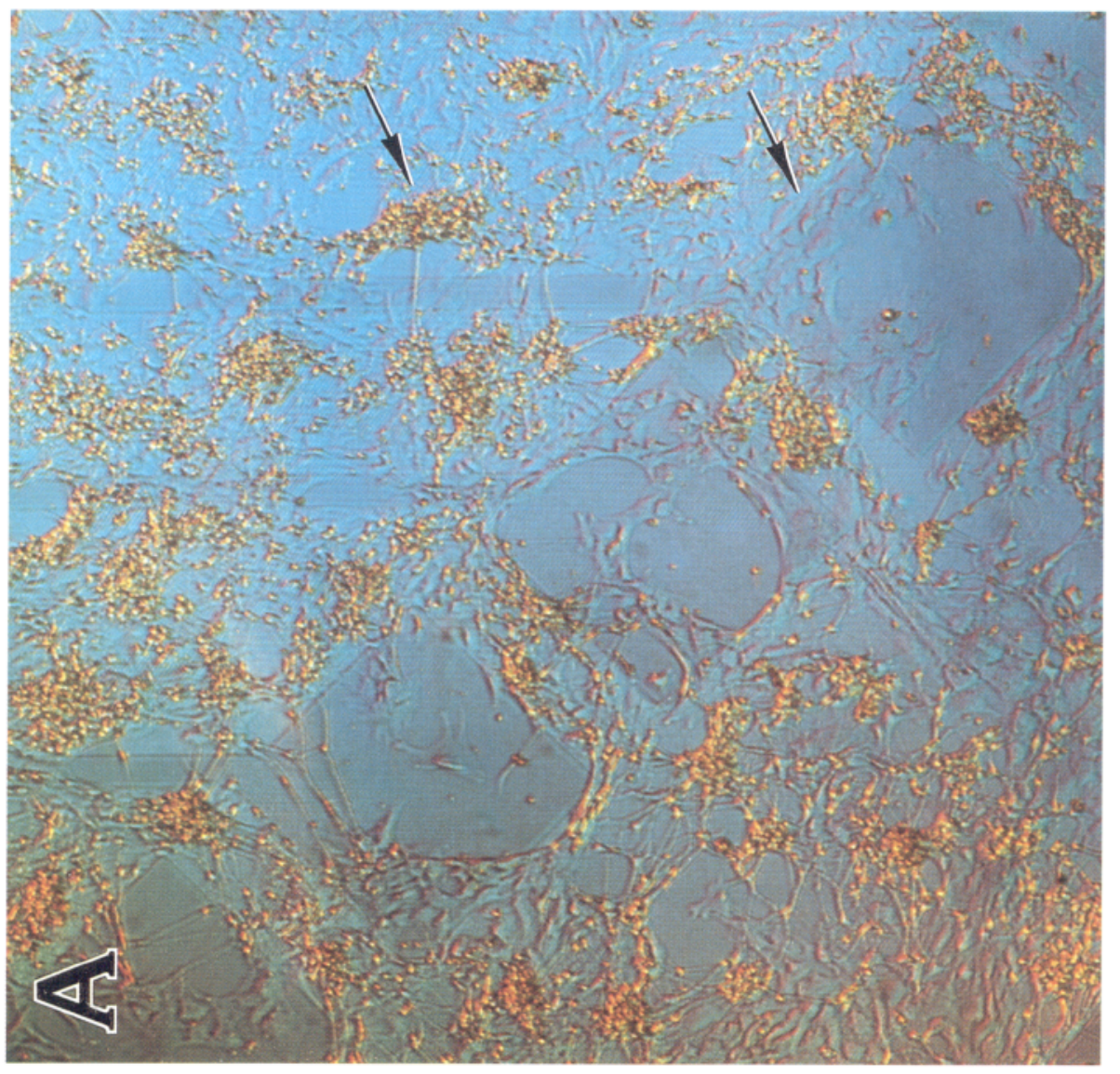

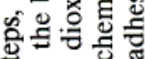

के

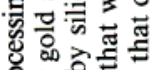

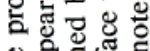

은

要 可的

过

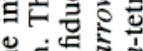
छ छ்

염 氞言

을

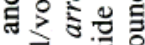

क월

जै

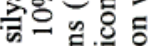

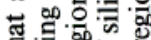

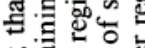

on

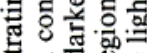

등

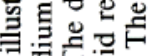

政

政

讨

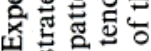

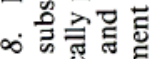

ข

将 

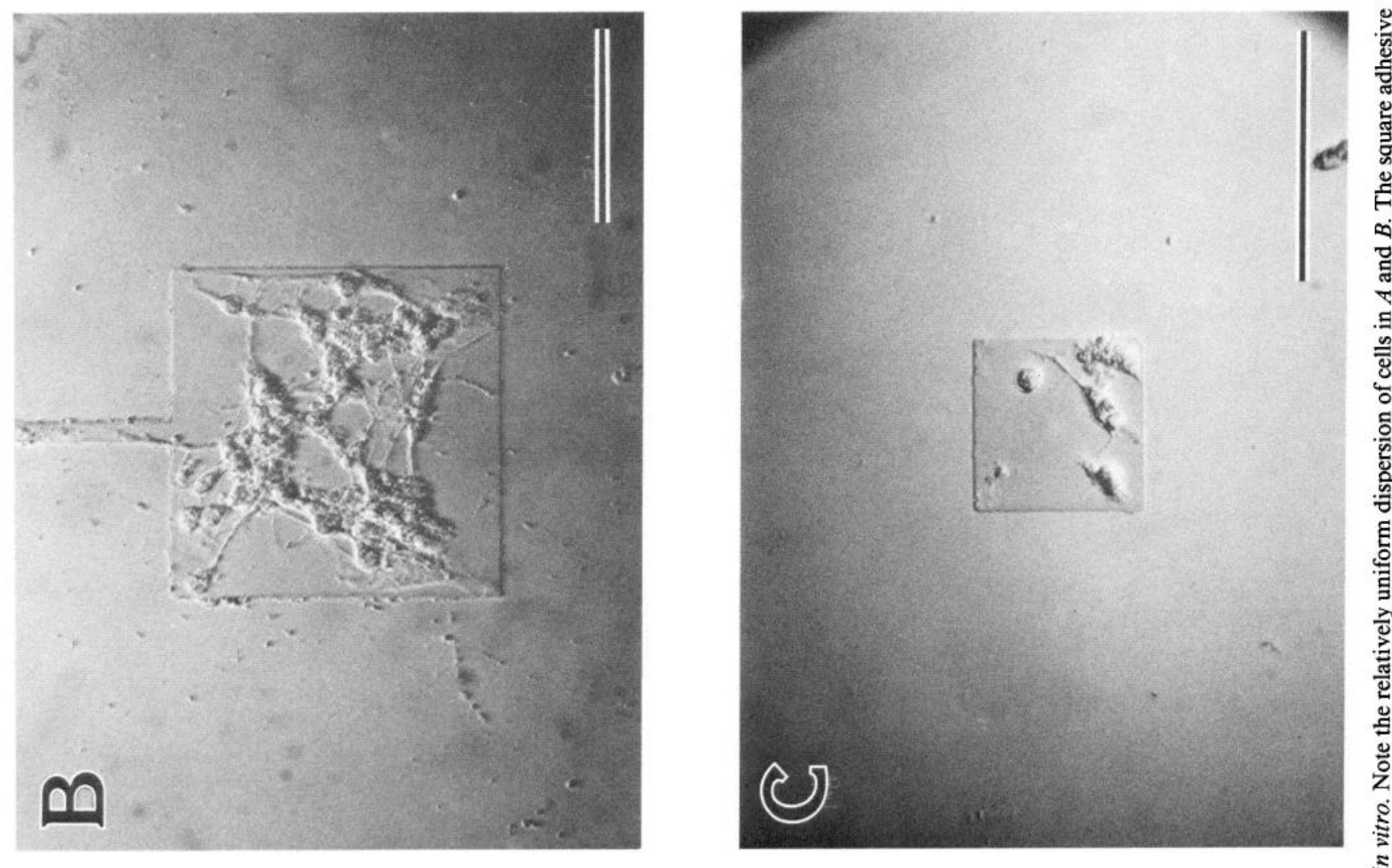

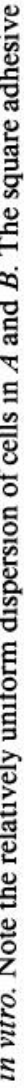
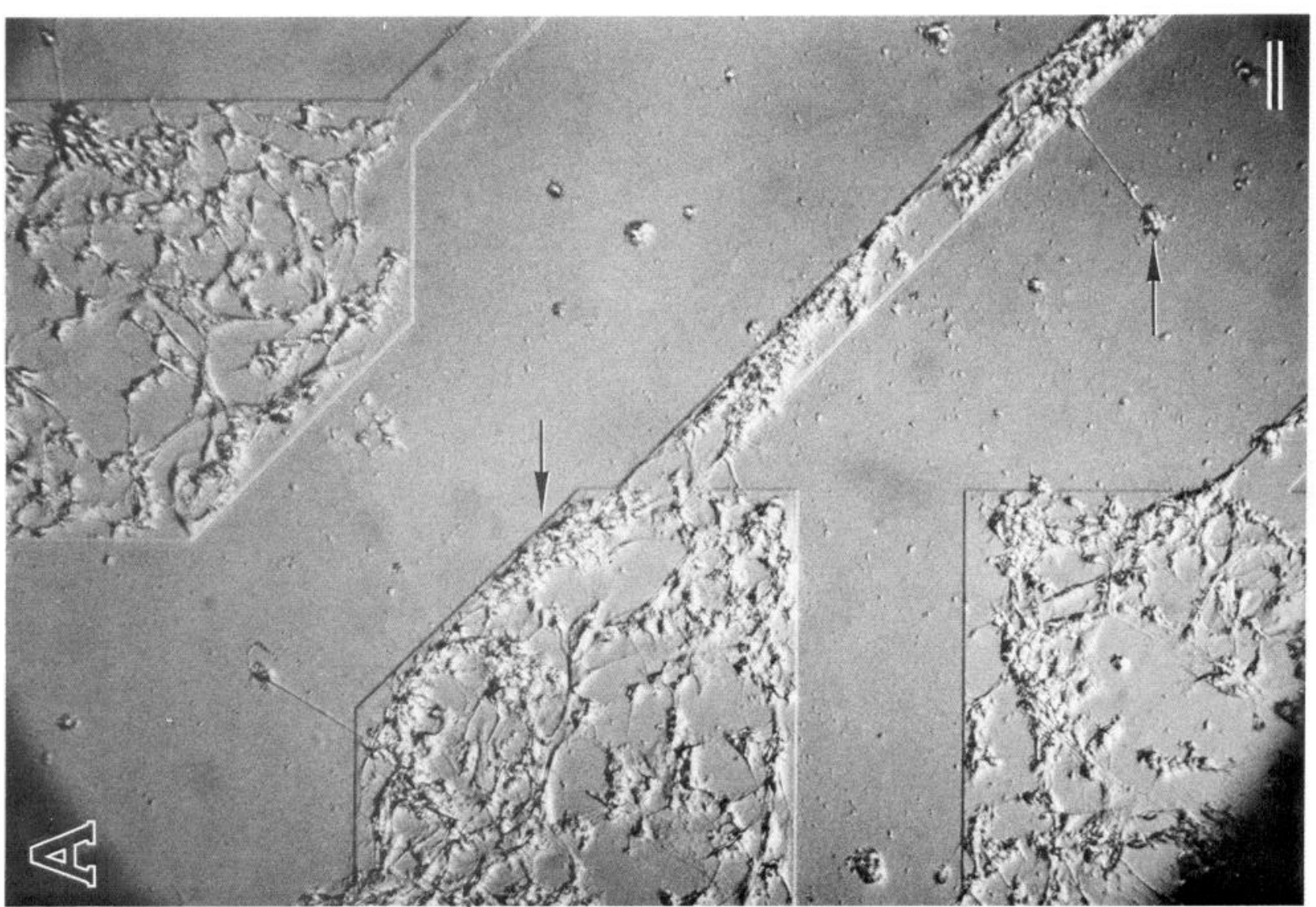

気望

巡롤

응

क्ष

递

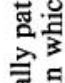

겅.

홍ํㅀㅇ

동

융 苍

它 药

출

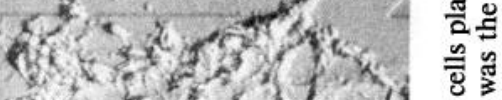

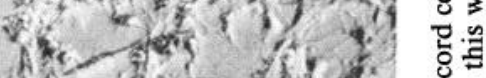

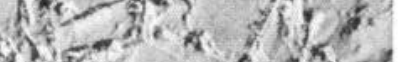
tain $\div$ है।

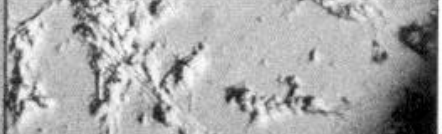

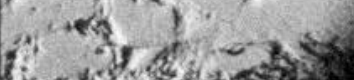
丞 2.5 


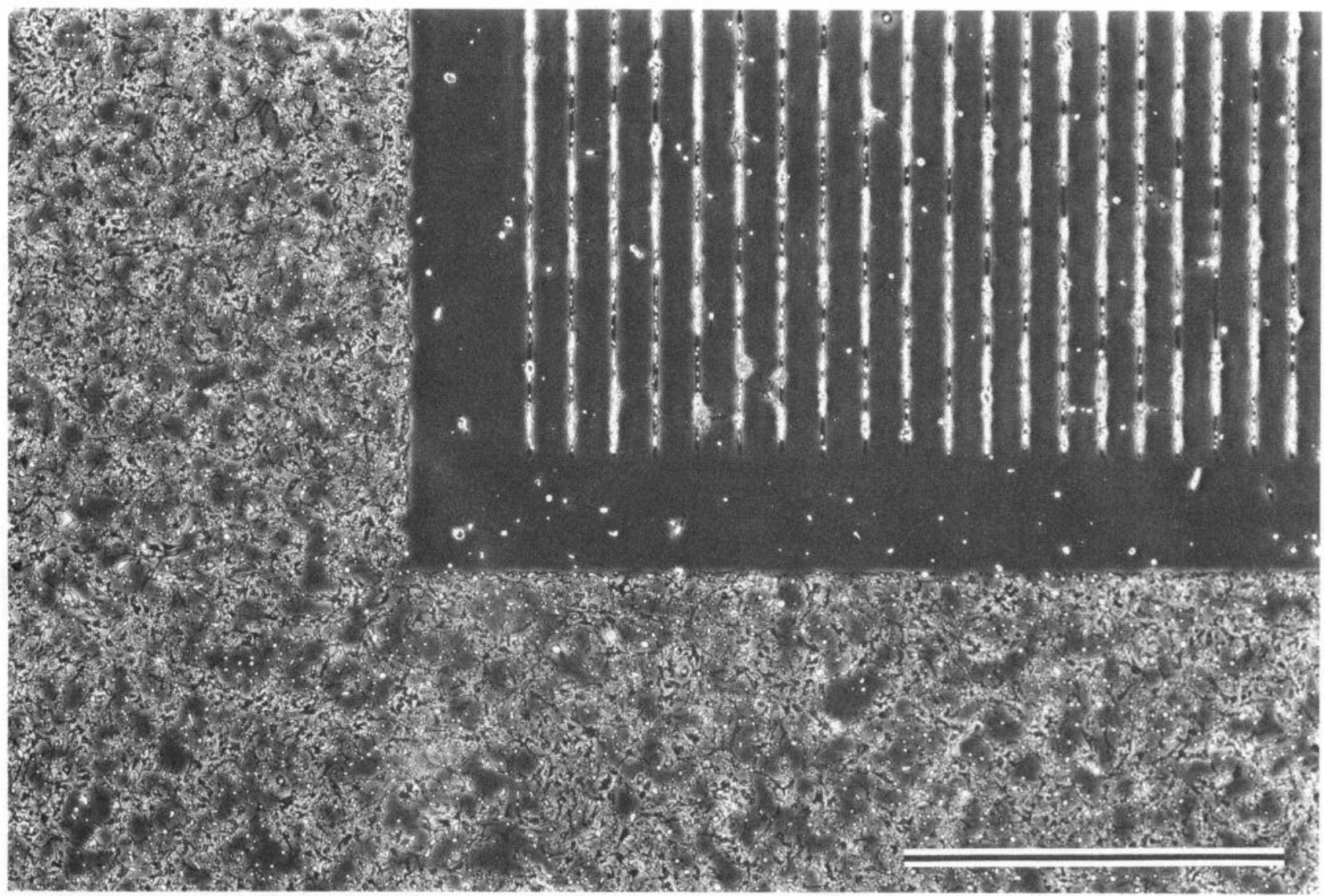

Figure 10. Illustration of a corner of the moat of "feeder" cells that surrounds a patterned region. The feeder cells assist in the long-term survival of the patterned cells. Shown is a culture of dissociated cerebellar cells after $2 \mathrm{~d}$ in vitro. The bright spots on the lines correspond to cell bodies, and the dark areas correspond either to cell processes or to glia. The full pattern of lines is shown in Figure 11. It consisted of 8 sets of parallel lines, each $10 \mu \mathrm{m}$ wide and $5000 \mu \mathrm{m}$ long. A set contained 100 lines, grouped as 10 subsets of 10 lines. The spacing between lines was constant within a group but varied from 10 to $100 \mu \mathrm{m}$, in steps of $10 \mu \mathrm{m}$, between groups. Scale bar, $1000 \mu \mathrm{m}$.

section, cerebellar cells formed well-defined patterns on properly processed substrates.

Influence of fiducials. The substrates used in the above experiments (Figs. 6-9) contained $\mathrm{SiO}_{2}$ fiducials that were used to mark areas bound with EDA-P. Although the height of these fiducials was much smaller than the characteristic size of the cells, i.e., $0.2 \mu \mathrm{m}$ versus $\sim 10 \mu \mathrm{m}$, we checked if the fiducials influenced the final pattern of cell adhesion.

A substrate was prepared in which a grid-like region (e.g., Fig. 6) bound with EDA-P was offset from a preexisting grid-like $\mathrm{SiO}_{2}$ fiducial. Dissociated cerebellar cells plated onto this surface were observed to pattern in a manner that reflected the underlying chemical pattern and not the pattern of the fiducial. These cultures appeared similar to the culture shown in Figure $6 B$. This result indicates that the fiducials used in this work had no discernible effect on pattern of cell adhesion.

\section{Longevity and development of cerebellar cells on patterned substrates}

We studied the conditions necessary to insure the long-term viability of dissociated cells on patterned substrates, as well as the pattern attained by those cells. This work was performed exclusively with cerebellar cells, for which we sought conditions that would allow for survival of the neurons for at least $10 \mathrm{~d}$ in vitro. This period corresponds to the the time required for granule cells in explant cultures of perinatal tissue to develop elec- trical excitability (Hockberger et al., 1987a). The cerebellar cells were grown on a quartz substrate containing a pattern of fine, parallel lines. Details of the pattern, which consisted of $10-\mu \mathrm{m}$ wide lines spaced from 10 to $100 \mu \mathrm{m}$ apart, are shown in Figures 10 and 11 . This pattern is suggested by the parallel organization of the axons of granule neurons in the molecular layer of the cerebellum (e.g., Eccles et al., 1977).

Plating requirements. The density of cells in a culture plays a crucial role in cell survival, particularly for central neurons (Fishbach and Nelson, 1977). Thus, the optimum plating density is a balance between maintaining a density sufficiently high to assure cell survivability, while simultaneously not overpopulating the culture so that cells are forced to aggregate.

Three features proved crucial for maintaining the integrity of cerebellar cells on the fine lines. First, the culture required a "feeder" colony of cells. We formed a feeder colony by constructing an adhesive moat around the patterned lines; a corner of the moat is shown in Figure 10. The feeder region encompassed approximately $75 \%$ of the total area of the surface.

Second, we found that postnatal cells survived only if they were isolated from the cerebella of P1-P5 animals. Cells from older animals, e.g., P9 or P10, initially adhered to the patterned surfaces, but after $1 \mathrm{~d}$ in vitro detached from regions with fine lines. The poor adhesion of cells from older animals may be a consequence of the relatively small population of glia in these preparations (see below). 

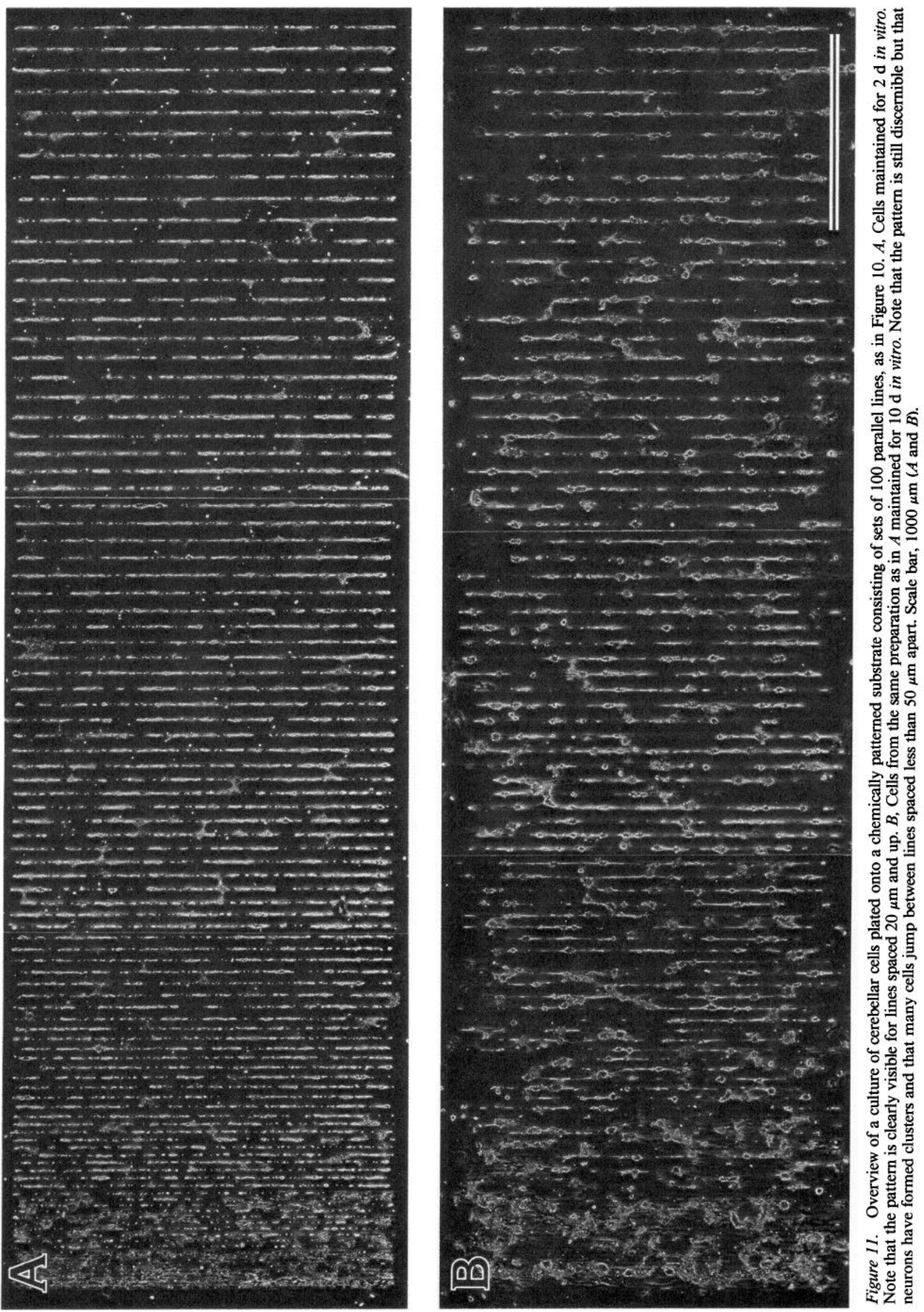

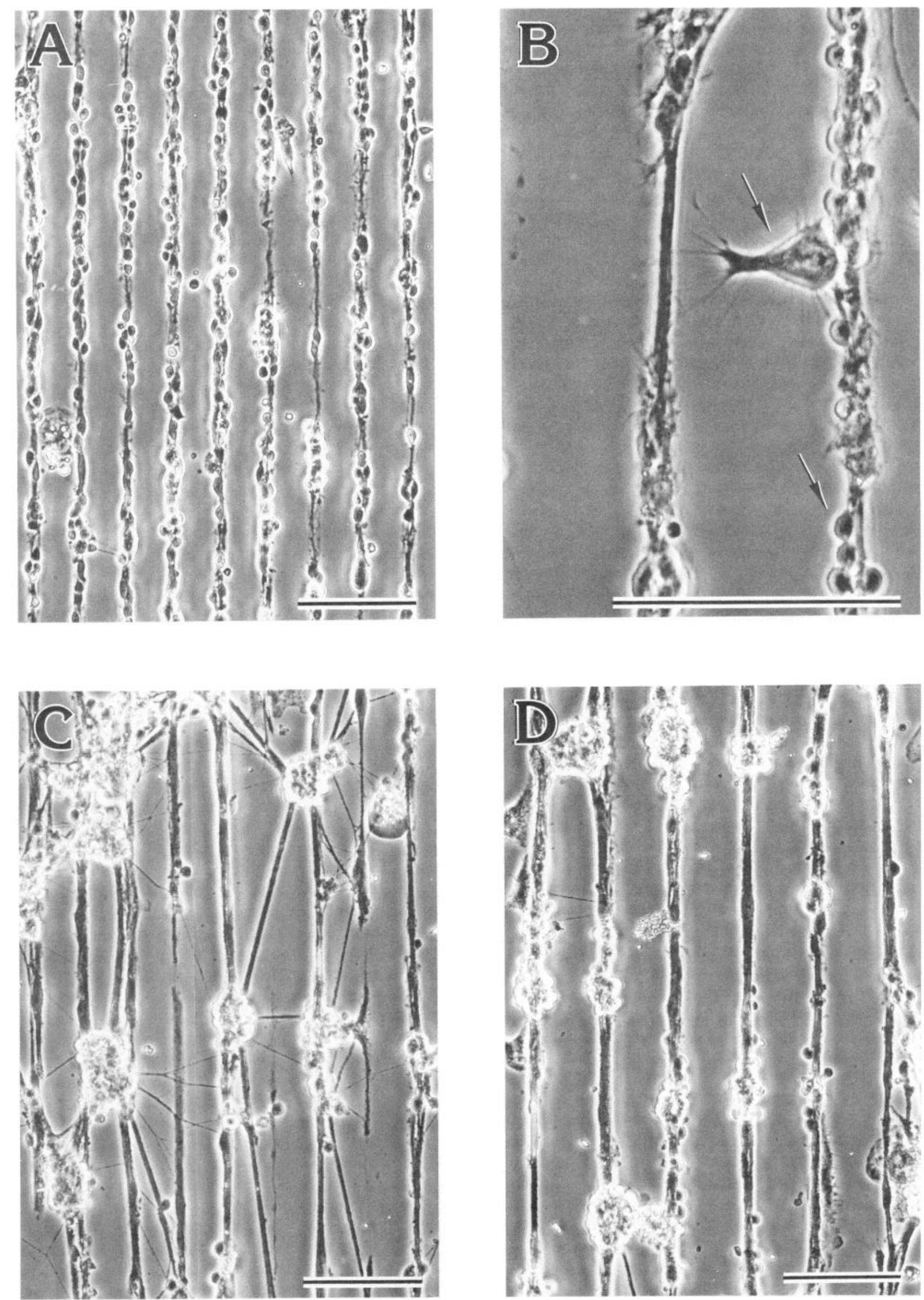
Last, we established a minimum plating density that assured the long-term survivability of the cultures. A dilution series of dissociated cells was prepared that yielded plating densities of $1 \times 10^{5}$ to $20 \times 10^{5} \mathrm{cells} / \mathrm{cm}^{2}$. Division of the cells in vitro was inhibited by the addition of a mitotic inhibitor, cytosine arabinoside, to the culture media (see Materials and Methods). We observed that granule cells survived on the lines for at least 12 $\mathrm{d}$ in vitro if the cultures were plated at densities at or above 8 $\times 10^{5}$ cells $/ \mathrm{cm}^{2}$. Cells in cultures plated at a density of $5 \times 10^{5}$ cells $/ \mathrm{cm}^{2}$ or less died or detached from the surface within the first 3-5 d. As an upper limit to the plating density, we observed that cells plated at a density near or above $10 \times 10^{5} \mathrm{cells} / \mathrm{cm}^{2}$ were clearly overcrowded; many of the cells in these cultures formed clumps within the first few days in vitro.

Cultures maintained for $2 \mathrm{~d}$ and for $10 \mathrm{~d}$ in vitro on the pattern of fine lines are shown in Figures $11, A$ and $B$, respectively. After $2 \mathrm{~d}$ in vitro the cells faithfully adhered to lines spaced as close as $30 \mu \mathrm{m}$. A detail of this feature is shown in Figure $12 \mathrm{~A}$; the small cell bodies correspond to granule neurons (next section). In addition to observing granule cells on the lines, we observed instances in which relatively large cells spanned the region of low adhesion between lines. The morphology of some of these large cells corresponded to that of cultured Purkinje neurons (Hockberger et al., 1987b; see Fig. 12B).

Cerebellar cells maintained for $10 \mathrm{~d}$ in vitro remained faithful to the underlying pattern for lines spaced by $50 \mu \mathrm{m}$ or more (Fig. 12D). Cells maintained on lines separated by $30 \mu \mathrm{m} \mathrm{di-}$ gressed from the underlying pattern, in contrast to the growth pattern observed after $2 \mathrm{~d}$ in vitro (cf. Fig. 12, $A$ and $C^{\prime}$ ). However, a spacing of $50 \mu \mathrm{m}$ was sufficiently small to allow Purkinje neurons to span adjacent rows of patterncd granulc cclls (Fig. $12 B)$.

Immunoreactivity for NSE. Immunohistological staining of the cultures was performed using polyclonal antibodies against NSE. This antigen is specific to neurons, as opposed to glia, in the cerebellum (Marangos et al., 1980; Schmechel et al., 1980). In particular, "immature" granular neurons in explant cultures react weakly with antibodies against NSE, while those in "developed" cultures ( $10 \mathrm{~d}$ in vitro) react strongly with this antibody (Hockberger et al., 1987a). Thus, a positive antigenic response of small (4-6 $\mu \mathrm{m})$ cells in culture confirms the identity of these cells as granule neurons. It also provides evidence for proper development of the glycolytic enzymatic pathway in these neurons (e.g., Marangos and Schmechel, 1987).

A culture of cerebellar cells maintained on patterned surfaces for $10 \mathrm{~d}$ in vitro and subsequently stained for immunoreactivity against NSE is shown in Figure 13A. The dark staining of the cluster of small cells indicates that these cells are granule neurons. Their axons, also darkly stained, are seen to migrate along the line bound with EDA-P. Weakly staining cells that spanned that width $(10 \mu \mathrm{m})$ of the lines were observed to coexist with both the axons and cell bodies (arrow, Fig. 13A). These com- panion cells most likely correspond to Bergmann glia (see below).

The staining characteristics of the cultures maintained on patterned substrates was essentially identical to that on unpatterned EDA-P and p-D-L substrates. These characteristics were similar to those observed in cultures of explant tissue (Hockberger et al., 1987a) and in studies of cerebellar development in vivo (Schmechel et al., 1980). These results imply that the granule neurons in our culture system are viable and undergo normal differentiation.

Immunoreactivity for GFAP. Immunohistological staining of the cultures was performed using polyclonal antibodies against GFAP. This antigen is specific to astroglia in the cerebellar cortex (Bignami and Dahl, 1973, 1975; DeBlas, 1984).

A culture of cerebellar cells maintained for $10 \mathrm{~d}$ in vitro on a pattern of lines and subsequently stained for immunoreactivity against GFAP is shown in Figure $13 B$. The darkly stained fibers correspond to processes emanating from glia. The lightly stained cell bodies (hematoxylin counterstain) correspond to granule neurons. As in the culture stained for immunoreactivity against NSE (Fig. 13A), the granule neurons were observed to be closely associated with the glia (arrow, Fig. 13B).

The GFAP-positive glia appeared to be constrained to the shape of patterned lines. To ascertain the unconstrained morphology of these cells, we stained cultures of cerebellar cells maintained on p-D-L-coated surfaces as well as on unpatterned surfaces bound with EDA-P. The morphology of the glia was vastly affected by the choice of substrate. Glia on p-D-L substrates attained primarily a spindle-shaped appearance (Fig. 14A). In contrast, cultures maintained on EDA-P surfaces contained glia that were primarily tile-shaped in appearance (Fig. 14B). The stained region of these glia did not overlap each other, in contrast with the overlap observed among processes of the spindle-shaped cells.

The cell bodies of granule neurons were always near or touching a spindle-shaped glia in cultures maintained on EDA-P surfaces. In regions where both spindle- and tile-shaped glia abut each other, the neurons consistently congregated with the spindle-shaped glia (Fig. 14C).

Electrophysiology of granule neurons. We examined the electrical properties of granule neurons plated and maintained on patterned surfaces as well as unpatterned p-D-L and EDA-P surfaces. Four criteria were assessed: the resting potential of the cell, the amplitude and time course of the inward and outward currents measured under voltage clamp, the form of the action potential measured under current clamp, and the response to glutamate. The observed values for each of these criteria were compared with the results for granule neurons in cultures of explant tissue (Hockberger et al., 1987a).

Granule neurons maintained for $2 \mathrm{~d}$ in vitro on surfaces bound with EDA-P had resting potentials of approximately $-30 \mathrm{mV}$. They exhibited only leakage currents or small outward currents

\footnotetext{
Figure 12. Details of cultures of cerebellar cells plated and maintained on chemically patterned quartz substrates, with a pattern as in Figures 10 and 11 . $A$ and $B$, Cells maintained for $2 \mathrm{~d}$ in vitro. In $A$, granule neurons are faithfully patterned on lines separated by $30 \mu \mathrm{m}$. In $B$, Purkinje neuron (upper arrow) is seen to bridge the nonadhesive region between 2 lines, separated by $60 \mu \mathrm{m}$, containing granule neurons (lower arrow); note the fine filaments emanating from the ascending dendrite of the Purkinje cell. $C$ and $D$, Cells maintained for $10 \mathrm{~d}$ in vitro. In $C$, this older culture is no longer faithful to lines separated by $30 \mu \mathrm{m}$ (cf. $A$ and $C$ ), but in $D$, these cells were faithful to patterns of lines separated by $50 \mu \mathrm{m}$. Scale bar, 100 $\mu \mathrm{m}(A-D)$.
} 
Figure 13. Immunoreactivity of dissociated cerebellar cells maintained for $10 \mathrm{~d}$ in vitro on a patterned surface. The pattern consists of 10 wide lines (Figs. 10-12). Immunoreactive regions appear dark (peroxidase staining) and cell nuclei appear medium gray (hematoxylin staining). $A$, Immunoreactivity for NSE. The darkly stained cell bodies and their processes correspond to granule neurons. Note that the processes share the adhesive line with unstained cells (arrow), presumably Bergmann glia. B, Immunoreactivity for GFAP. The darkly stained processes correspond to Bergmann glia. Note that the lightly stained neurons cluster around the patterned glia (arrow). Scale bar, $10 \mu \mathrm{m}(A$ and $B$ ).
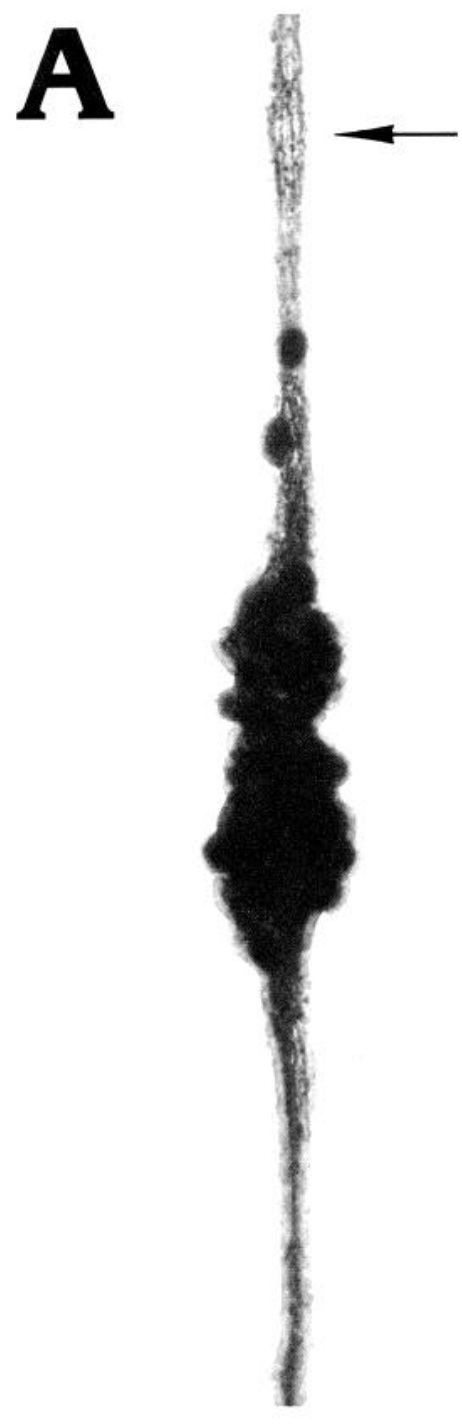

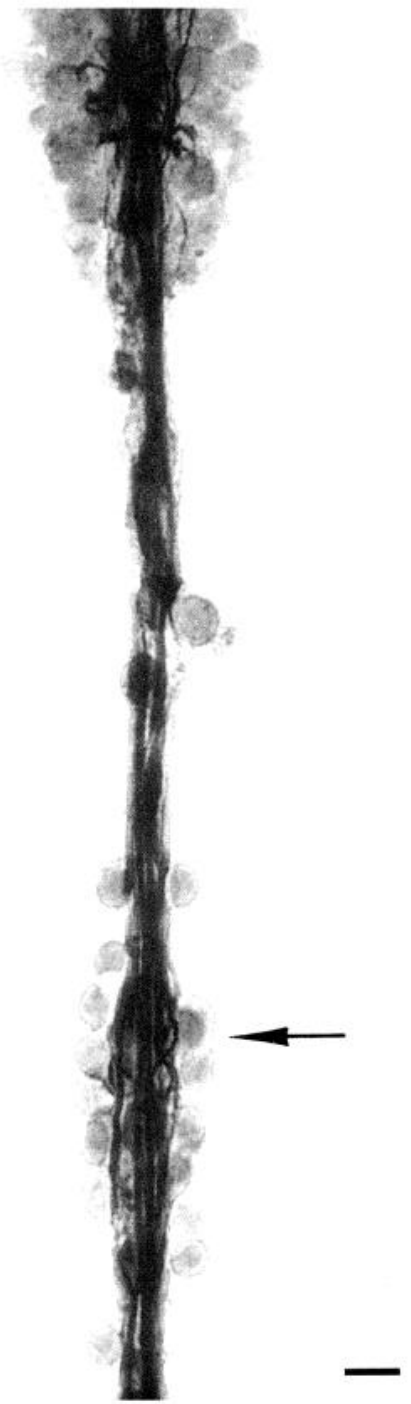

under voltage clamp and were not electrically excitable. Similar results were observed with 2 d cultures on p-D-L-coated surfaces. These results were essentially identical to the activity observed with "immature" granule cells in explant cultures (Hockberger et al., 1987a).

After $10 \mathrm{~d}$ in vitro the resting potential of patterned granule neurons (lower arrow, Fig. $12 \mathrm{~B}$ ) was between -55 and $-60 \mathrm{mV}$. Typical membrane currents evoked with these cells under voltage clamp are shown in Figure $15 \mathrm{~A}$. The shape of the inward and outward currents were similar to those observed with "intermediate" granule neurons in explant cultures (Hockberger et al., 1987a). The delayed, negative-going deflections in the observed currents are presumed to originate from action potentials generated in the axon (e.g., Hirano et al., 1986).

Action potentials were observed in response to a pulse of depolarizing current (Fig. 15B); the amplitude of these spikes indicate that they are produced in the soma. This neuron also exhibited a strong burst of axonally generated action potentials following the application of glutamate (Fig. 15C). Similar spiking activity, along with similar resting potentials and current records, was observed for cells maintained on unpatterned surfaces bound with EDA-P or coated with p-D-L.

Dissociated granule neurons maintained for $30 \mathrm{~d}$ in vitro on either EDA-P or p-D-L (unpatterned) surfaces showed exclusively axonal currents. The glutamate response of these cells was typically absent. These results parallel the activity observed with "mature" granule neurons in explant cultures (Connor et al., 1987).

Electrophysiology of Purkinje neurons. We studied the development of electrical activity in dissociated Purkinje neurons maintained on both EDA-P and p-D-L surfaces. These cells were obtained from embryonic (E21) animals rather than postnatal (P2-P5) ones; the older animals yielded relatively small numbers of identifiable Purkinje cells that, in addition, did not differentiate in vitro (cf. Hockberger et al., 1987b).

Purkinje cells were first examined after $10 \mathrm{~d}$ in vitro. At this age they appeared similar in morphology to the $2 \mathrm{~d}$ Purkinje neurons obtained from P4 animals (Fig. 12B). Voltage-clamp records of these cells indicated that both inward and outward currents were present for cultures maintained on both EDA-P and p-D-L surfaces. The Purkinje neurons generated action potentials at the soma in response to small current pulses. No glutamate response was observed. Similar results were found for Purkinje neurons dissociated from postnatal animals (P4) maintained $2 \mathrm{~d}$ in vitro (upper arrow, Fig. $12 B$ ).

The activity of Purkinje neurons maintained on EDA-P for 

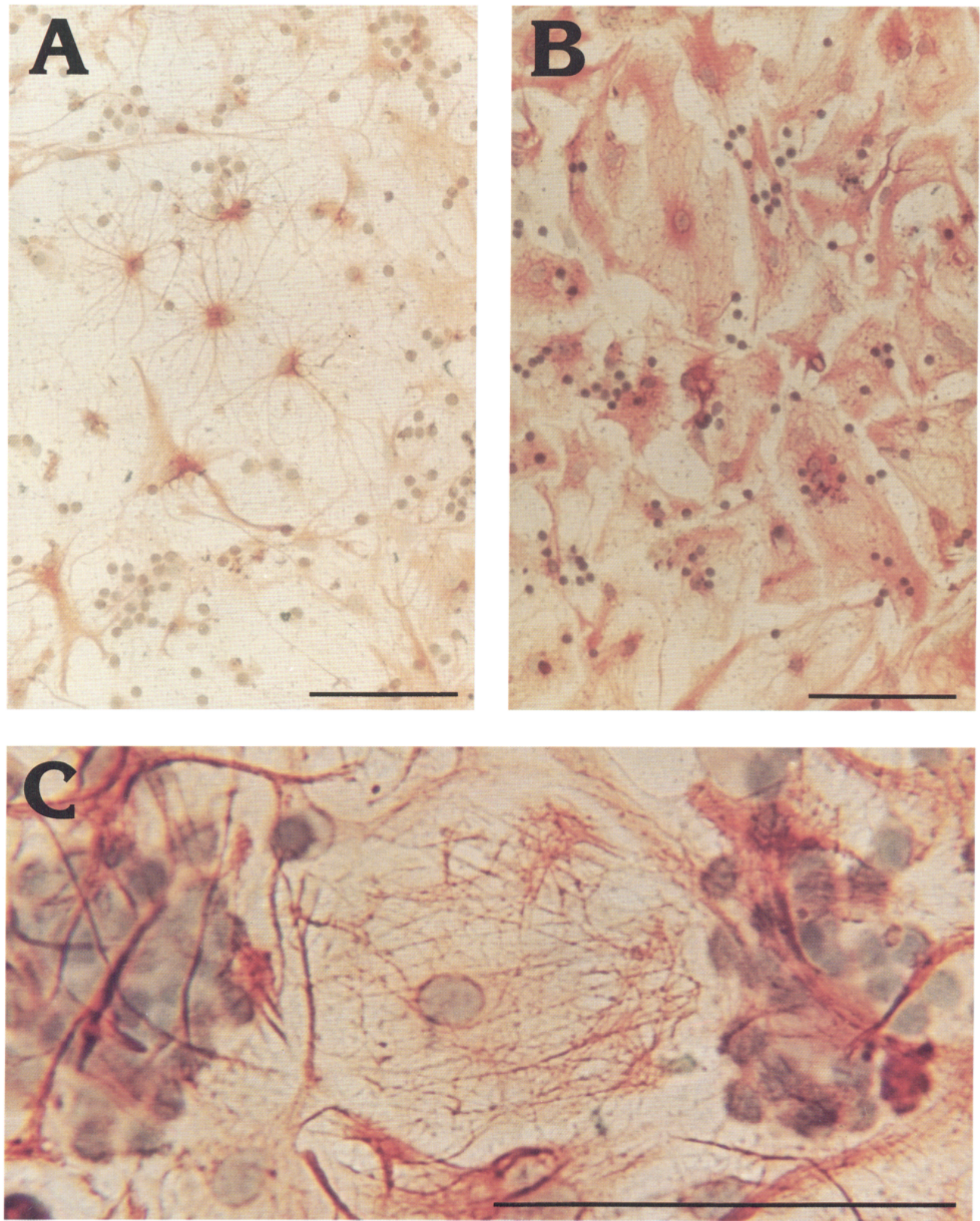

Figure 14. Dissociated cerebral cells stained for immunoreactivity against GFAP. Cells were maintained for $10 \mathrm{~d}$ in vitro on unpatterned substrates. Immunoreactive regions appear red (peroxidase staining) and cell nuclei appear blue-gray (hematoxylin staining). $A$, Culture maintained on coverglass coated with $\mathrm{p}$-D-L. Note the predominance of process-bearing positive stained cells. The granule neurons appear as blue-gray dots. $B$, Culture maintained on coverglass bound with EDA-P. Note the predominance of flat, fibroblast-like positive stained cells. $C$, Region on an EDA-P bound surface that shows both process-bearing glia and fibroblast-shaped glia (arrow). This culture was plated at 1.5 times the density of the cultures in $A$ and $B$ to emphasize the preferential segregation of the neurons. Note that the granule neurons favor contact with the process-bearing glia. Scale bar, $100 \mu$ m plates. 

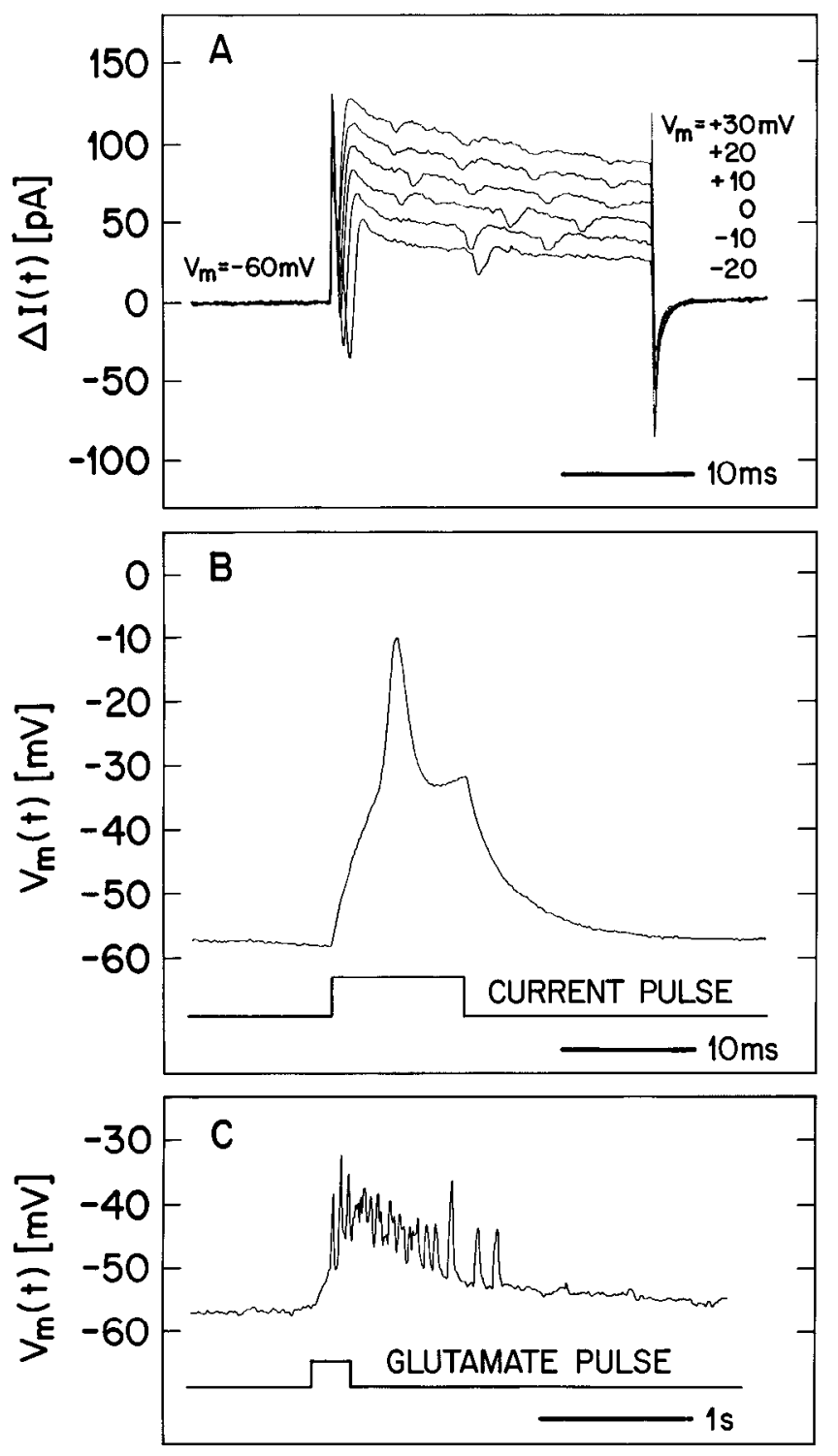

TIME

Figure 15. Electrical activity of granule neurons maintained for $10 \mathrm{~d}$ in vitro on a patterned quartz surface. $A$, Currents, $\Delta I$, measured under voltage clamp from a holding potential of $V_{m}=-60 \mathrm{mV}$. The depolarizing voltage was systematically stepped between +40 and $+90 \mathrm{mV}$; the final potentials are indicated. $B$, Transmembrane voltage, $V_{m}$, measured under current clamp. The data show an action potential induced by a $25 \mathrm{pA}$ depolarizing pulse of current. $C$, Membrane depolarization measured under current clamp in response to an extracellular pulse of glutamate; note that the amplitudes of the spikes in this record were partially suppressed by the bandwidth of the instrumentation.

$30 \mathrm{~d}$ in vitro is shown in Figure 16. The inward current was lypically larger than that observed after $10 \mathrm{~d}$ in vitro. The spiking characteristics of these cells were studied under current clamp. Injection of a small depolarizing current resulted in soma-generated action potentials (Fig. 16B); the spikes were $20-30 \%$ larger than those observed after $10 \mathrm{~d}$ in vitro. These cells also exhibited a membrane depolarization following an extracellular pulse of glutamate (Fig. 16C). The electrical activity observed in the $30 \mathrm{~d}$ Purkinje neurons maintained on our surfaces was similar to that reported for Purkinje cells grown in other culture
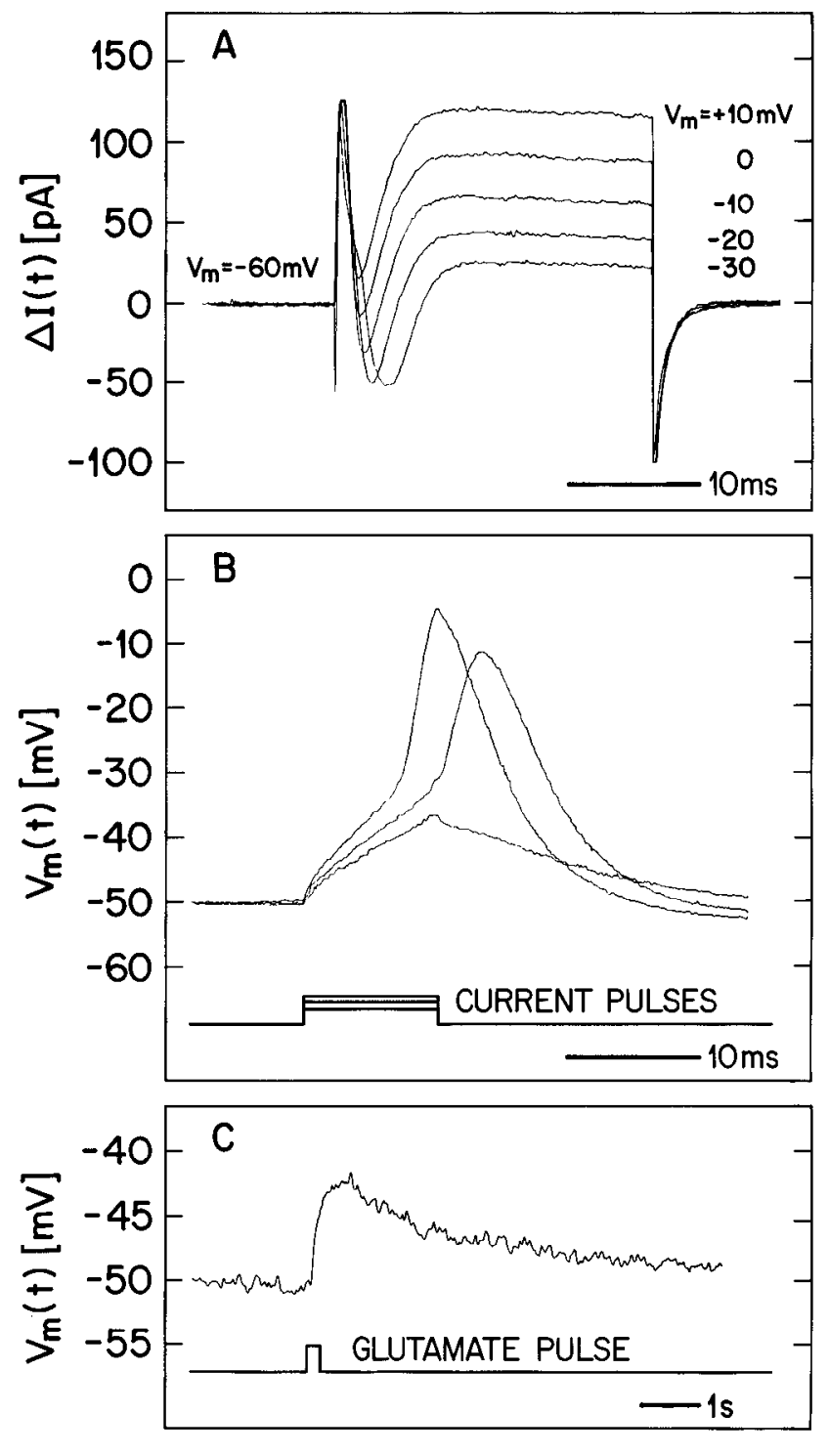

TIME

Figure 16. Electrical activity of Purkinje neurons maintained for 30 $\mathrm{d}$ in vitro on coverglass bound with EDA-P. $A$, Currents, $\Delta I$, measured under voltage clamp from a holding potential of $V_{m}=-60 \mathrm{mV}$. The depolarizing voltage was systematically stepped between +30 and +70 $\mathrm{mV}$; the final potentials are indicated in the figure. $B$, Transmembrane potentials, $V_{m}$, measured under current clamp in response to depolarizing pulses of current. A current of $10 \mathrm{pA}$ elicited the subthreshold response. Action potentials were observed for currents of 15 and 20 pA. $C$, Membrane depolarization measured under current clamp in response to an extracellular pulse of glutamate.

systems (Gruol, 1983; Hirano and Ohmori, 1986; Gruol and Franklin, 1987; Hockberger et al., 1987b).

\section{Discussion}

The present study has demonstrated that dissociated neurons can be directed to adhere and grow in high-resolution patterns. These patterns were formed by the use of silane chemistry and lithographic processing to selectively modify the adhesive properties of the in vitro substrate. The patterned arrangement of cells was maintained for at least $12 \mathrm{~d}$ in vitro. During this time, cerebellar cells underwent normal morphological and physio- 
logical development. This shows that normal neuronal development will occur on these nonbiological materials.

\section{Patterning cells}

Our goal was to pattern growth of neurons and their support cells in a manner that can model some features of the cytoarchitecture attained by the tissue from which these cells originate. These model systems must be constructed in a manner that allows the development and electrical activity of the neurons to be monitored. Four criteria need to be satisfied to achieve this goal: Patterns of dissociated cells must be reproducible, the patterned cells must remain viable, the cells must remain faithful to the desired pattern while they develop electrical activity and synaptic connections, and the patterned outgrowth must be amcnablc to clcctrical rccording techniques.

A number of previous studies, beginning with the work of Carter $(1965,1968)$, have addressed the issue of selected adhesion of cells onto a substrate. Carter observed that fibroblasts adhered to palladium, but not to polyacetate. He exploited this difference in adhesion to confine fibroblasts to roughly $100 \mu \mathrm{m}^{2}$ islands of palladium that were evaporated onto a polyacetate film. These results were extended to other plastic films by Harris (1973). Similar techniques were used by Ivanova and Margolis (1973) to align fibroblasts on phospholipid films, by Letourneau (1975) to align DRG neurons on pathways formed by evaporated metal on polymer-coated substrates, by Cooper et al. (1976) to orient neuroblastoma cells on stripes of silicon monoxide, by Albrecht-Buehler (1979) to confine 3T3 cells to scratches on an evaporated surface, and by Bray (1984) to confine DRG neurons to islands of silicon monoxide. Letourneau and coworkers (Hammarback et al., 1985; Hammarback and Letourneau, 1986) also demonstrated that neurite outgrowth can be directed by selectively photoinactivating regions on a surface that was coated with laminin, a glycoprotein which promotes cell adhesion (Timpl and Heilwig, 1979). These studies addressed a number of critical issues in the development of individual cells. However, the procedures used to pattern cell growth did not maintain both the viability of the cells and the pattern of outgrowth for a time sufficiently long for developing neurons to attain electrical excitability.

A system in which neurons were both localized and grown to electrical maturity was the microculture system of Furshpan et al. (1976). This culture system proved invaluable for studies of transmitter development in superior cervical ganglion neurons. However, the size of the adhesive islands used in that study, approximately $500 \mu \mathrm{m}$, are too large to recreate details of neural architectures in vitro.

The present study has extended the previous work in this field in a number of ways. The viability and the pattern of cerebellar cells in our system were maintained for a time commensurate with the development of electrical excitability by the neurons. I he procedures we describe offer excellent reproducibility and high-resolution patterns. Cells were maintained on lines as fine as $5 \mu \mathrm{m}$. This sizc is comparable with the diamcter of the smallest neurons in mammals, the granule cells.

The procedures we used for patterning cells affords great flexibility in the design of the final pattern. The use of chemical procedures, rather than physical evaporation techniques, allows virtually any molecule to be bound to a silicon-based substrate. For example, molecules that cannot be formed into silane derivatives - such as the glycoproteins fibronectin (e.g., Kleinman et al., 1981), laminin (Timpl and Heilwig, 1979), and neural cell adhesion molecule (Buskirk et al., 1980)-can be patterned by first binding an amine derivative in the desired pattern and then binding the glycoprotein to the amine with chemical crosslinking reagents.

The silane derivatives that we used to control cell adhesion formed a molecular layer that was covalently bound to the substrate (Fig. 2). This feature insured that the patterned surfaces did not interfere with the optical properties of the substrate. In fact, the surface of a chemically patterned substrate appeared unaltered, i.e., there were no visual indications of the underlying pattern, prior to the plating of cells. The binding characteristics of these silanes also makes them compatible with a class of porous gold/silicon alloys whose electrical characteristics are suitable for constructing arrays of surface electrodes that are sensitive to neural activity (D. Kleinfeld, R. E. Miller, and G. E. Blonder, unpublished observations).

\section{Cell adhesion and development on artificial substrates}

We have shown that the adhesion of a variety of cell phenotypes, derived from either spinal cord or cerebellar tissue, can be controlled by covalently bonding small organic molecules to a surface. Surfaces bound with diamines (EDA-P) and triamines (DETA-P) promoted cell adhesion. Cultures maintained on these surfaces were similar in morphology to those maintained on conventional p-D-L surfaces (Figs. 4 and 5). These results imply that cells can adhere to rather simple molecules, as compared with the long-chain polyamines or the large biomolecules usually associated with promoting cell adhesion.

Cells adhered well to surfaces bound with molecules containing an ethylenediamine functional group but did not adhere to surfaces bound with monoamines. The adhesion propcrtics wcrc unaffected by small variations in the length of the spacing group between either the ethylenediamine or the monoamine and the surface. These results, and results on cell adhesion to charged polymers (McKeehan and Ham, 1976; Ruegg and Hefti, 1984), suggest that a positively charged group is a necessary but not sufficient requirement for cell adhesion. Our results further suggest that a specific chemical structure may facilitate cell adhesion. In particular, ethylenediamine is reported to act as a strong agonist to receptors for GABA (Bokisch et al., 1984).

The attachment of cells to a surface bound with an alkane, such as $n$-tetradecane, was inhibited by plating the cells in media containing $5-10 \%(\mathrm{vol} / \mathrm{vol})$ serum. The detailed role of the serum in the adhesion process was unclear from our studies, although it appeared to decrease the overall "stickiness" of the cells. This may be related to the observation that isolated invertebrate neurons will not stick to untreated glass surfaces when serum is present in the media (Schacher and Proshansky, 1983).

Dissociated cerebellar cells did not adhere to either untreated silicon or silicon dioxide surfaces. Dissociated spinal cells also did not adhere to untreated silicon, but they did adhere, albeit in clumps, to relatively large regions $(z 500 \mu \mathrm{m})$ of silicon dioxide (Fig. $9 A$ ). This result suggests that low-resolution control of spinal cell outgrowth, but not cerebellar cell outgrowth, can be attained using patterns of $\mathrm{SiO}_{2}$ on Si. Note that other, nonneuronal, cell types show a difference in their affinity for $\mathrm{SiO}_{2}$ versus Si (Grattarola et al., 1988).

The granule neurons maintained on patterned surfaces developed a mature immunoreactivity for NSE over the first 10 $\mathrm{d}$ in vitro (Fig. 13). This suggests that their maturation is unaffected by both the patterning and the underlying EDA-P surface. We also observed that the patterned granule neurons formed 
clusters, even with a mitotic inhibitor present, between 2 and $10 \mathrm{~d}$ in vitro (e.g., Fig. 12). This suggests that the neurons migrate on their associated glia, as reported by Edmondson and Hatten (1987).

Granule neurons and Purkinje neurons cultured on the amine bound surfaces developed electrical activity. The inward and outward currents in the developing granule neurons were similar to those examined in detail using explant cultures grown on p-D-L substrates (Hockberger et al., 1987a). The currents of Purkinje neurons were similar to those observed in studies of dissociated cerebellar cells grown on p-D-L substrates (Hockberger et al., 1987b). These results, together with the observed morphology and immunoreactivity of our cultures, imply that cerebellar neurons grown on our artificial substrates are essentially indistinguishable from those grown on conventional p-D-L substrates.

\section{Glia and their interaction with neurons}

Two forms of glia that were immunologically positive for GFAP were present in the cultures of dissociated cerebellar cells. Cultures plated and maintained on p-D-L substrates contained primarily spindle-shaped glia (Fig. 14A). The morphology of these cells is quite similar to the GFAP-positive astrocytes designated type 2, or process-bearing, by Raff et al. (1983). Cultures plated and maintained on EDA-P and other chemically treated substrates contained primarily tile-shaped glia (Fig. 14B). The morphology of these cells is quite similar to the GFAP-positive astrocytes designated type 1, or fibroblast-like, by Raff et al. (1983). In the study by Raff and coworkers, the relative density of type 1 versus type 2 glia depended on the choice of tissue used in the dissociation procedures. In the present study, the relative density depended on the choice of substrate.

How is the morphology of the GFAP-positive glia affected by the choice of substrate? One possibility is that the glia transform between type 1 and type 2 astrocytes. A second is that the 2 types of glia represent different cell lineages. Our observations support the first hypothesis. Many tile-shaped cells on EDA-P surfaces extended processes, indicative of glia with a partially transformed morphology (Fig. 14C).

In the course of our studies we observed that soluble factors, in addition to the chemical nature of the surface, can determine the morphology of the glia. When dissociated cerebellar cells were plated and maintained on EDA-P surfaces using defined media (Fisher, 1982; Ahmed et al., 1983; Kingsbury et al., 1985), as opposed to media supplemented with serum, only spindleshaped glia were present (unpublished observations). The transformation of tile-shaped astrocytes to spindle-shaped astrocytes, but not the reverse, has been observed in other in vitro populations (Lim et al., 1973; Moonen et al., 1975; Lindsay et al., 1982; Hatten, 1985).

When granule neurons were presented with the choice between spindle-shaped glia and tile-shaped glia, they segregated to the spindle-shaped glia (Fig. 14C). This implies that there is recognition between granule neurons and spindle-shaped glia. The preference of the granule neurons for a specific form of glia lends support to the radial-glia hypothesis (Rakic, 1971). This hypothesis states that glia oriented parallel to each other, i.e., the Bergmann glia, are required for the proper positioning of neurons in the cerebellum (Rakic, 1971; Hatten and Liem, 1981).

The selective preference of granule neurons to grow in proximity to the spindle-shaped glia suggests that these glia may influence the viability of the neurons. This issue was addressed by plating dissociated cerebellar cells onto surfaces bound with the triamine DETA-P (Fig. $5 D$ and unpublished results). These cultures appeared similar to those plated on p-D-L during the first $2 \mathrm{~d}$ in vitro (Fig. $5 D$ ). However, after $10 \mathrm{~d}$ in vitro only a small fraction of the granule neurons had survived. The cultures were then stained for GFAP immunoreactivity; a dense layer of tile-shaped glia were present, but very few spindle-shaped glia were observed. As a control for possible neurotoxic effects of DETA-P, cultures were concomitantly maintained on DETA-P surfaces using defined media. These cultures contain exclusively spindle-shaped glia (see above). We observed essentially no diminution in the number of granule neurons after 10 $\mathrm{d}$ in vitro (unpublished observations). These results imply that the survival of granule neurons is dependent on the presence of spindle-shaped GFAP-positive glia, as previously suggested (Hatten, 1985).

\section{Concluding remarks}

The present work is a step toward constructing simplified neural architectures in vitro. We have described a general procedure for patterning the location of cells and described the development of cerebellar neurons on the patterns. We were guided in our choice of cell type and the geometry of the pattern by the striking, ordered arrangement between Purkinje neurons and granule neurons observed in vivo. The dendrites of Purkinje neurons lie in a plane at right angles to a layer that contains the granule cell axons (e.g., Palay and Chan-Palay, 1974; Eccles et al., 1977). A next step in this work is the study of synaptic connections between Purkinje neurons and oriented lines of granule neurons, as illustrated by the arrangement in Figure $12 B$.

\section{References}

Ahmed, Z., P. S. Walker, and R. E. Fellows (1983) Properties of neurons from dissociated fetal rat brain in serum-free culture. J. Neurosci. 3: 2448-2462.

Albrecht-Buehler, G. (1979) The angular distribution of directional changes of guided 3T3 cells. J. Cell Biol. 80: 53-60.

Bignami, A., and D. Dahl (1973) Differentiation of astrocytes in the cerebellar cortex and the pyramidal tracts of the newborn rat. An immunofluorescence study with antibodies to a protein specific to astrocytes. Brain Res. 49: 393-402.

Bignami, A., and D. Dahl (1975) Astrocyte-specific protein and neuroglial differentiation. An immunofluorescence study with antibodies to the glial fibrillary acidic protein. J. Comp. Neurol. 153: 27-38.

Bokisch, A. J., J. M. Bold, C. R. Gardner, M. N. Perkins, C. J. Roberts, T. W. Stone, and R. J. Walker (1984) The action of gamma-aminobutyric acid (GABA) and ethylenediamine (EDA) on Limulus and Helix central neurons and rat cerebellar and sympathetic ganglion neurons. Gen. Pharmacol. 15: 497-504.

Bray, D. (1984) Axonal growth in response to experimentally applied mechanical tension. Dev. Biol. 102: 379-389.

Buskirk, D. R., J.-P. Thiery, U. Rutishauser, and G. M. Edelman (1980) Antibodies to a neural cell adhesion molecule disrupt histogenesis in cultured chick retina. Nature $285: 488-489$.

Carter, S. B. (1965) Principles of cell motility: The direction of cell movement and cancer invasion. Nature 208: 1183-1187.

Carter, S. B. (1968) A method of confining single cells to study individual cell reactions and clone formation. Exp. Cell Res. 48: 189193.

Connor, J. A., H.-Y. Tseng, and P. E. Hockberger (1987) Depolarization- and transmitter-induced changes in intracellular $\mathrm{Ca}^{2+}$ of rat cerebellar granule cells in explant cultures. J. Neurosci. 7: 1384-1400.

Cooper, A., H. R. Munden, and G. L. Brown (1976) The growth of mouse neuroblastoma cells in controlled orientations on thin films of silicon monoxide. Exp. Cell Res. 103: 435-439.

DeBlas, A. L. (1984) Monoclonal antibodies to specific astroglial and neuronal antigens reveal the cytoarchitecture of the Bergmann glia fibers in the cerebellum. J. Neurosci. 4: 265-273. 
Eccles, J. C., M. Ito, and Z. Szentagothai (1977) The Cerebellum as a Neuronal Machine, Springer-Verlag, Berlin.

Edmondson, J. C., and M. E. Hatten (1987) Glial guided granule neuron migration in vitro: A high-resolution time-lapse video microscope study. J. Neurosci. 7: 1928-1934.

Fedoroff, S., and L. Hertz (1977) Cell, Tissue and Organ Cultures in Neurobiology, Academic, New York.

Fishbach, G. D., and P. G. Nelson (1977) Cell culture in neurobiology. In Handbook of Physiology, Section 1, The Nervous System, Vol. 1, E. R. Kandel, ed., pp. 719-774, American Physiology Society, Bethesda, MD.

Fisher, G. (1982) Cultivation of mouse cerebellar cells in serum-free, hormonally defined media: Survival of neurons. Neurosci. Lett. 28: 325-329.

Furshpan, E. J., P. R. MacLeish, P. H. O'Lague, and D. D. Potter (1976) Chemical transmission between rat sympathetic neurons and cardiac myocytes developing in microcultures: Evidence for cholinergic, adenergic and dual-function neurons. Proc. Natl. Acad. Sci. USA 73: $4225-4229$.

Gerstein, G. L., M. J. Bloom, I. E. Espinosa, S. Evanczuk, and M. R. Turner (1983) Design of a laboratory for multineuronal studies. IEEE Trans. Sys. Man Cybern. 13: 668-683.

Grattarola, M., M. Tedesco, A. Cambiaso, G. Perlo, G. Giannetti, and A. Sanguineti (1988) Cell adhesion to silicon substrata: Characterization by means of optical and acoustic cytometric techniques. Biomaterials 9: 101-106.

Gruol, D. L. (1983) Cultured cerebellar neurons: Endogenous and exogeneous components of Purkinje cell activity and membrane response to putative transmitters. Brain Res. 263: 223-241.

Gruol, D. L., and C. L. Franklin (1987) Morphological and physiological differentiation of Purkinje neurons in cultures of rat cerebellum. J. Neurosci. 7: 1271-1293.

Hammarback, J. A., and P. C. Letourneau (1986) Neurite extension across regions of low cell-stratum adhesivity: Implications for the guidepost hypothesis of axonal pathfinding. Dev. Biol. 117: 655-662.

Hammarback, J. A., S. A. Palm, L. T. Furcht, and P. C. Letourneau (1985) Guidance of neurite outgrowth by pathways of substratumabsorbed laminin. J. Neurosci. Res. 13: 213-220.

Harris, A. (1973) Behavior of culture cells on substrata of variable adhesiveness. Exp. Cell Res. 77: 285-297.

Hatten, M. E. (1985) Neuronal regulation of astroglial morphology and proliferation in vitro. J. Cell Biol. 100: 384-396.

Hatten, M. E., and R. K. H. Licm (1981) Astroglia cells provide a template for the organization of cerebellar neurons in vitro. J. Cell Biol. 90: 622-630.

Hirano, T., and H. Ohmori (1986) Voltage-gated and synaptic currents in rat Purkinje cells in dissociated cell cultures. Proc. Natl. Acad. Sci. USA 83: 1945-1949.

Hirano, T., Y. Kubo, and M. Wu (1986) Cerebellar granule cells in culture: Monosynaptic connections with Purkinje cells and ionic currents. Proc. Natl. Acad. Sci. USA 83: 4957-4961.

Hockberger, P. E., H.-Y. Tseng, and J. A. Connor (1987a) Immunocytochemical and electrophysiological differences of rat cerebellar granule cells in explant cultures. J. Neurosci. 7: 1370-1383.

Hockberger, P. E., H.-Y. Tseng, and J. A. Connor (1987b) Electrophysiological properties of cerebellar Purkinje cells after dissociation from late embryonic and early postnatal rats. Soc. Neurosci. Abstr. 13: 1119 .

Hubel, D. H., and T. N. Wiesel (1977) Functional architecture of macaque monkey visual cortex. Proc. R. Soc. Lond. [Biol.] 198: 159.

Ireland, G. W., P. Dopping-Hepenstal, P. Jordan, and C. O'Neill (1987) Effects of patterned surfaces of adhesive islands on the shape, cytoskeleton, adhesion and behavior of Swiss mouse 3T3 fibroblasts. J. Cell Sci. Suppl. 8: 19-33.

Ivanova, O. Y., and L. B. Margolis (1973) The use of phospholipid film for shaping cell cultures. Nature 242: 200-201.

Kingsbury, A. E., V. Gallo, P. L. Woodhams, and R. Balazs (1985) Survival, morphology and adhesion properties of cerebellar interneurons cultured in chemically defined and serum-supplemented medium. Dev. Brain Res. 17: 17-25.

Kleinfeld, D., and P. E. Hockberger (1987) Patterning the location of dissociated cerebellar cells on artificial substrates. Soc. Neurosci. Abstr. 13: 259.

Kleinfeld, D., and D. W. Tank (1986) Control of neuronal-substratum adhesion using surface modification and photolithographic techniques. Biophys. J. (Abstr.) 49: 233a.

Kleinman, H. K., R. J. Klebe, and G. R. Martin (1981) Role of collagenous matrices in the adhesion and growth of cells. J. Cell Biol. 88: 473-485.

Lasher, R. S., and I. S. Zagon (1972) The effect of potassium on neuronal differentiation in cultures of dissociated newborn rat cerebellum. Brain Res. 41: 482-488.

Letourneau, P. C. (1975) Cell-to-substratum adhesion and guidance of axonal elongation. Dev. Biol. 44: 92-101.

Leyden, D. E., and W. T. Collins (1980) Silyated Surfaces, Gordon and Breach, New York.

Lim, R., K. Mitsunobu, and W. K. P. Li (1973) Maturation-stimulating effect of brain extract and dibutylcyclic AMP on dissociated embryonic brain cells in culture. Exp. Cell Res. 79: 243-246.

Lindsay, R. M., P. C. Barber, M. R. C. Sherwood, J. Zimmer, and G. Raisman (1982) Astrocyte cultures from adult rat brain. Derivation, characterization and neurotropic properties of pure astroglial cells from corpus callosum. Brain Res. 243: 329-343.

Marangos, P. J., and D. E. Schmechel (1987) Neuron specific enolase: A clinically useful marker for neurons and neuroendocrine cells. Annu. Rev. Neurosci. 10: 269-295.

Marangos, P., D. Schmechel, A. Parma, and F. Goodwin (1980) Developmental profile of neuron-specific (NSE) and non-neuronal (NNE) enolase. Brain Res. 190: 185-193.

McGillis, D. A. (1983) Lithography. In VLSI Technology, S. M. Sze, ed., pp. 267-280, McGraw-Hill, New York.

McKeehan, W. L., and R. G. Ham (1976) Stimulation of clonal growth of normal fibroblasts with substrata coated with basic polymers. J. Cell Biol. 71: 727-734.

Messer, A. (1977) The maintenance and identification of mouse cerebellar granule cells in monolayer culture. Brain Res. 130:1-12.

Moonen, G., Y. Cam, M. Sensenbrenner, and P. Mandel (1975) Variability of the effects of serum-free medium, dibutyryl cyclic AMP or theophylline on the morphology of cultured newborn rat astrocytes. Cell Tissue Res. 163: 365-372.

Nelson, P. G., and M. Lieberman (1981) Excitable Cells in Tissue Culture, Plenum, New York.

Nevo, A., A. DeVries, and A. Katchalsky (1955) Interaction of basic polyamino acids with the red blood cell. Biochim. Biophys. Acta 17: 536-547.

Palay, S. L., and V. Chan-Palay (1974) Cerebellar Cortex: Cytology and Organization, Springer-Verlag, New York.

Pleuddemann, E. P. (1982) Silane Coupling Agents, Plenum, New York.

Raff, M. C., E. R. Abney, J. Cohen, R. Lindsay, and M. Nobel (1983) Two types of astrocytes in cultures of developing rat white matter: Differences in morphology, surface gangliosides and growth characteristics. J. Neurosci. 3: 1289-1300.

Rakic, P. (1971) Neuron-glia relationship during granule cell migration in developing cerebellar cortex. A Golgi and electron microscopic study in Macacus rhesus. J. Comp. Neuro. 141: 283-312.

Ransom, B. R., E. A. Neale, M. Henkart, P. N. Bullock, and P. G. Nelson (1977) Mouse spinal cord in cell culture. I. Morphology and intrinsic neuronal electrophysiologic properties. J. Neurophys. 40: $1132-1150$.

Romijn, H., A. Habets, M. Mud, and P. Walters (1982) Nerve outgrowth, synaptogenesis and bioelectric activity in fetal rat cerebral cortex tissue cultured in serum-free, chemically defined media. Dev. Brain Res. 2: 583-589.

Ruegg, U. T., and F. Hefti (1984) Growth of dissociated neurons in culture dishes coated with synthetic polymeric amines. Neurosci. Lett. 49: 319-324.

Schacher, S., and E. Proshansky (1983) Neurite regeneration by Aplysia neurons in dissociated cell culture: Modulation by the Aplysia hemolymph and the presence of the initial axonal segment. J. Neurosci. 3: 2403-2413.

Schmechel, D. M., M. Brightman, and P. Marangos (1980) Neurons switch from non-neuronal enolase to neuron-specific enolase during differentiation. Brain Res. 190: 195-214.

Seil, F. J., A. L. Leiman, and W. R. Woodward (1980) Cytosine arabinoside effects on developing cerebellum tissue culture. Brain Res. 186: $393-408$.

Thangnipon, W. A., A. E. Kingsbury, M. Webb, and R. Balazs (1983) Observations on rat cerebellar cells in vitro: Potassium concentration 
and relationship between neurons and astrocytes. Dev. Brain Res. 11: 177-189.

Timpl, R., and R. Heilwig (1979) Laminin: A glycoprotein from basement membrane. J. Biol. Chem. 254: 9933-9937.

Vossen, J. L., and W. Kern (1978) Thin Film Processes, Academic, New York.
Yavin, E., and Z. Yavin (1974) Attachment and culture of dissociated cells from rat embryo cerebral hemispheres on polylysine-coated surface. J. Cell. Biol. 62: 540-546. 